Universidade de São Paulo

Instituto de Física e Química de São Carlos

\title{
Proposta e Simulação de uma
} Arquitetura RISC

Fredy João Valente

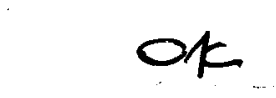

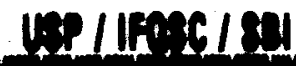
$2-2 z^{n+2+\infty} x^{2}$

\begin{abstract}
Dissertação apresentada ao
Instituto de Física e Química de São Carlos

para obtenção do título de

Mestre em Física Aplicada.
\end{abstract}

Orientador: Prof.Dr. Carlos Antonio Ruggiero

Departamento de Física e Ciência dos Materiais

São Carlos - 1991 


\section{UNIVERSIDADE DE SÃO PAULO}

INSTITUTO DE FÍSICA E QUIMICA DE SÃO CARLOS

MEMBROS DA COMISSA JULGADORA DA DISSERTAGAO DE MECTRADO DE FREOY JUAO UALENTE APRESENTAOA AO

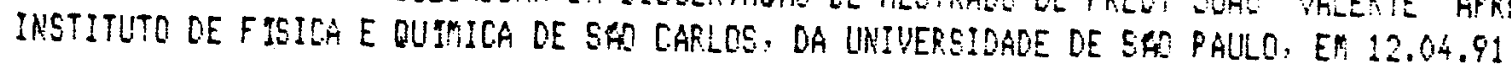

COMISEAO JULGBORA:

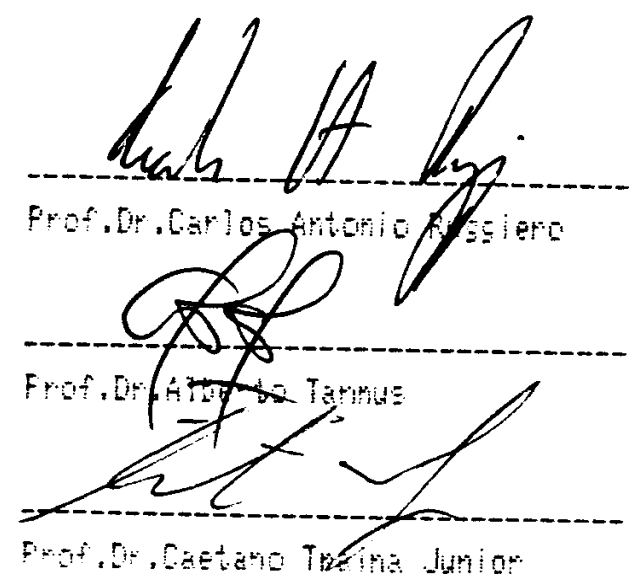


A meus pais, Antonio e Carmem 


\section{Agradecimentos}

Gostaria de agradecer a todos que, de uma forma ou de outra contribuiram pela realização deste trabalho. Em especial:

. ao Prof. Ruggiero pelo grande incentivo e pela grande influência em minha formação profissional.

- ao Prof. Jan Slaets pela grande colaboração profissional e pelas discussões técnicas.

. aos engenheiros André e Mateus.

. a Lia pelos trabalhos de secretaria.

- a Benê pela confecção dos desenhos.

aos colegas de laboratório, Fernando, Gonzalo, Mônica, Agma e Caetano. aos amigos Totó, Edson e Paulo Ruffino.

a todo o pessoal do Laboratório de Instrumentação Eletrônica.

- a todo o pessoal do Laboratório de Ressonância Magnética. 


\section{Conteúdo}

Resumo iv

Abstract $\quad$ v

1 Introdução 1

1.1 Definição RISC . . . . . . . . . . . . . . . . . . . . . 1

1.2 Suporte para linguagens de alto nível $\ldots \ldots \ldots \ldots$

2 Natureza da arquitetura RISC $\quad \mathbf{8}$

2.1 Conjunto de Instruções . . . . . . . . . . . . . . . . . . . 8

2.2 Organização Orientada a Registrador . . . . . . . . . . . . . . . 9

2.3 Acesso à memória e modos de endereçamento . . . . . . . . . . . . . 11

2.4 Transferência de controle com atraso . . . . . . . . . . . . . . . 12

2.5 Instrução de formato fixo . . . . . . . . . . . . . . . . . 14

2.6 Banco de registradores . . . . . . . . . . . . . . . . 15

2.6 .1 Janelas de registradores entrelaçadas . . . . . . . . . . . . 16

2.6.2 Organização circular das janelas de registradores . . . . . . . . . 17

2.7 Pipeline . . . . . . . . . . . . . . . . . . . 20 20

2.7.1 Modelo de pipeline empregado em RISC . . . . . . . . . . . 20

2.7.2 Suspensão do pipeline durante acesso à memória . . . . . . . . . . . 21

2.8 Memória Cache . . . . . . . . . . . . . . . . . . . . . 24

2.8.1 Cache do processador Clipper(Fairchild) . . . . . . . . 25

$\begin{array}{lrr}3 & \text { A Arquitetura Proposta } & 29\end{array}$

$3.1 \quad$ RISC-LIE . . . . . . . . . . . . . . . . . . 29 
3.1 .1 Micro arquitetura . . . . . . . . . . . . . . 30

3.1.2 Caminhos dos dados na execução de instrução . . . . . . . . . . . 32

4 O Simulador RISC-LIE $\quad 39$

4.1 Modelo de simulação . . . . . . . . . . . . . . . . . . . 39

4.2 Geração do Modelo . . . . . . . . . . . . . . . . . . . . . . 40

4.3 Simulação do Modelo . . . . . . . . . . . . . . . . . . . . . . . 41

4.4 Comandos do Simulador . . . . . . . . . . . . . . . . . . . . . 44

4.5 Estatísticas apontadas pelo simulador . . . . . . . . . . . . . . . 45

$\begin{array}{lll}5 & \text { Desempenho } & 47\end{array}$

5.1 Dhrystone Benchmark . . . . . . . . . . . . . . . . . . 47

5.2 Resultados obtidos no IFQSC . . . . . . . . . . . . . . . . 49

Conclusões e Futuros Trabalhos

A Características Arquiteturais $\quad \mathbf{5 5}$

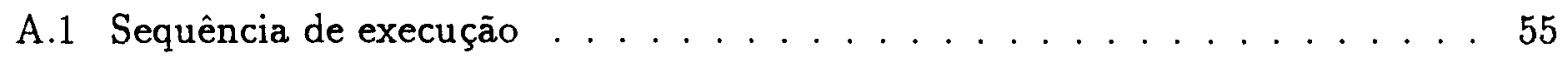

A.2 Conjunto de instruções . . . . . . . . . . . . . . . 55

A.2.1 Instruções OP registrador-registrador . . . . . . . . . . 56

A.2.2 Instruções load . . . . . . . . . . . . . . . . . . 59

A.2.3 Instruções store . . . . . . . . . . . . . . . 60 60

A.2.4 Instruções de transferência de controle . . . . . . . . . . 60

A.2.5 Miscelânia de instruções . . . . . . . . . . . . . . . . 63

$\begin{array}{lc}\text { Bibliografia } & 65\end{array}$ 


\section{Lista de Figuras}

2.1 Esquema de desvio atrasado (delayed branch) . . . . . . . . . . . . . 13

2.2 Formatos de instrução . . . . . . . . . . . . . . . . . . 15

2.3 Janelas de tamanho fixo entrelaçadas . . . . . . . . . . . . . . . . 16

2.4 Organização circular das janelas de registradores . . . . . . . . . . . . . 18

2.5 Pipeline do RISC II . . . . . . . . . . . . . . . . . . . . . . 21

2.6 Dependência de dado e endereço no pipeline . . . . . . . . . . . . . 22

2.7 Suspensão do pipeline durante acesso à memória . . . . . . . . . . . . . . 23

2.8 Set Associativity. . . . . . . . . . . . . . . . . . . 26

2.9 Cache do processador Clipper . . . . . . . . . . . . 27

3.1 Micro Arquitetura RISC-LIE . . . . . . . . . . . . . . . . . . . 32

3.2 Caminhos para a ULA . . . . . . . . . . . . . . . . 34

3.3 Caminhos para o Shifter ....................... 35

3.4 Fluxo através de DST . . . . . . . . . . . . . . 37

3.5 Fluxo de dados de/para memória . . . . . . . . . . . . . 38

A.1 Instruções shift e lógicas aritméticas . . . . . . . . . . . . . . . 58

A.2 Instruções load . . . . . . . . . . . . . . . . . . . . . 59

A.3 Instruções store . . . . . . . . . . . . . . . . . . . . . . 60

A.4 Transferência de controle e jump atrasado . . . . . . . . . . . 62 


\section{Lista de Tabelas}

1.1 Porcentagem dinâmica de operandos em Pascal e C. . . . . . . . . . . . . 6

1.2 Peso relativo $(\%)$ de declarações em alto nível . . . . . . . . . . . . 7

2.1 Sintetizando instruções em RISC . . . . . . . . . . . . . . . . . . 11

2.2 Sintetizando modos de endereçamento em RISC . . . . . . . . . . . . . 12

5.1 Declarações no Dhrystone . . . . . . . . . . . . . . . . . . . 48

$5.2 \quad$ Resultados do Dhrystone . . . . . . . . . . . . . . . . . . . . . . . . . . . . 49

5.3 Resultados do Dhrystone no IFQSC . . . . . . . . . . . . . . . . 50

A.1 Conjunto de instruções RISC.LIE . . . . . . . . . . . . . . . . . 57

A.2 Condições de $j u m p \ldots \ldots \ldots \ldots$. . . . . . . . . . . . . . 64 


\section{Resumo}

RISC - Uma nova tendência em arquitetura de computadores. Este trabalho apresenta um estudo de como surgiu esta nova arquitetura, e suas características básicas, que a diferencia das arquiteturas convencionais. Uma proposta de microprocessador RISC é apresentada, com sua rota de dados completamente detalhada.

Um simulador para arquitetura RISC foi então construído, para se testar este microprocessador.

Para validar o simulador, que é a idéia principal deste trabalho, e para se avaliar a arquitetura do microprocessador proposto, usou-se o benchmark Dhrystone, e os resultados foram comparados com máquinas comerciais. 


\section{Abstract}

RISC - A new trend in computer architecture. This work presents a study of how this new architecture emerged, and the basic caracteristics that diferentiate it from the conventional architectures. A proposed RISC microprocessor is presented with the completely detailed data-path.

A simulator for the RISC architecture was built to test this microprocessor.

To validate the simulator, which is the main idea of this work, and to evaluate the architecture of the proposed microprocessor, the Dhrystone benchmark was used and the results were compared with commercial machines. 


\section{Capítulo 1}

\section{Introdução}

RISC, uma sigla para Reduced Instruction Set Computer, é um estilo de arquitetura de computadores que enfatiza simplicidade e eficiência.

\subsection{Definição RISC}

Desde os mais antigos computadores de programa armazenado, os conjuntos de instruções têm se tornado cada vez maiores e mais complexos. O MARK-1 de 1948, possuía somente sete instruções de complexidade mínima, tal como adds e jumps simples; já máquinas contemporâneas como as da linha VAX, possuem centenas de instruções. Além de numerosas, elas podem ser extremamente complicadas, a ponto de inserir atomicamente um elemento em uma lista duplamente ligada, ou avaliar um polinômio em ponto-flutuante de grau arbitrário. Qualquer melhora que se queira no desempenho de uma nova implementação de um VAX, terá que considerar as complexas técnicas de implementação existentes, tais como pipeline ${ }^{1}$, prefetching (busca adiantada de instruções) e execução de instrução em multi-ciclos.

Esta progressão de um conjunto de instruções pequeno e simples, para um grande e complexo, aconteceu também com o desenvolvimento de processadores integrados em uma única pastilha, na década de setenta. O Motorola 68020 por exemplo, possui 11 modos de endereçamento a mais que o 6800 , mais que o dobro das instruções, e ainda suporte para cache e co-processadores. Não só o número de instruções e modos de endereçamento aumentou, mas também sua complexidade.

\footnotetext{
${ }^{1}$ não se traduziu pipeline por ser um termo comum em arquitetura de computadores
} 
Esta tendência em direção a máquinas CISC (Complex Instruction Set Computer) foi influenciada dentre muitos aspectos, pelas seguintes coisas:

- Novos modelos dentro de uma mesma família de computadores requerem compatibilidade com os anteriores, resultando num sempre crescente número de instruções e na propagação de características.

- Muitos projetistas de computadores tentaram reduzir o gap semântico entre programas e o conjunto de instruções do computador, adicionando instruções semânticamente próximas daquelas utilizadas pelos programadores. Esperava-se com isso uma redução no custo do software, através de uma máquina de fácil programação. Tais instruções tendem a ser muito complexas, devido a seu alto nível semântico, e ainda corre-se o risco de tal instrução não satisfazer determinadas características requeridas pela linguagem em uso.

- Na tentativa de desenvolver uma máquina mais veloz, os projetistas constantemente moviam funções de software para microcódigo, e de microcódigo para hardware, sem se preocupar com os efeitos adversos que, uma determinada característica adicionada à arquitetura, pudesse causar à implementação. Por exemplo, a adição de uma instrução, requer um circuíto lógico adicional para sua decodificação, tornando o conjunto de instruçôes um pouco mais lento (este fenômeno é conhecido como $n+1$ [Colw85]).

- Ferramentas e metodologias, ajudavam os projetistas no manuseio da complexidade inerente de largas arquiteturas.

Microcodificação é um interessante exemplo de técnica, que incentivou a realização de muitos projetos CISC. Em primeiro lugar, ela permite uma maneira estruturada de criar e alterar eficientemente algorítmos que controlam a execução de numerosas operações e instruções complexas em um computador. Em segundo lugar, a proliferação de características CISC é em boa parte devida à natureza quântica das memórias de microcódigo; é relativamente fácil adicionar-se um novo modo de endereçamento, ou uma instrução obscura a uma máquina, desde que seu espaço de microcódigo não esteja totalmente ocupado. 
Execuções passo a passo de instruções (traces), em máquinas CISC, mostram que poucas das instruções disponíveis, são de fato usadas na maioria dos programas. Esta situação levou John Cocke (IBM) a pensar num novo estilo de computadores, diferentes dos tradicionais. Iniciou-se então em meados da década de 70 o projeto "801", que recebeu este nome devido ao número do prédio do grupo de pesquisa envolvido no projeto. A máquina seria baseada em tecnologia ECL e usaria um compilador bastante avançado.

Pouco foi publicado sobre este projeto desde então, mas de acordo com George Radin [Radi83], o conjunto de instruções seria tal que as operações em tempo de execução, são aquelas que:

- não poderiam ser movidas para o tempo de compilação,

- não poderiam ser mais eficientemente executadas pelo código objeto, produzido por um compilador que entendeu a intenção do programa em alto nível,

- poderiam ser implementadas mais eficientemente em lógica randômica, que por uma sequência equivalente de instruções de software.

A máquina contaria com um compilador que usaria muitas estratégias de otimização, para obtenção de alta eficiência, incluindo um poderoso esquema de alocação de registradores. A sua implementação foi guiada por um desejo de simplicidade, e caracterizada por controle via hardware e execução de instrução em um único ciclo de máquina. Sua arquitetura era de 32 bits, 32 registradores, e os acessos à memória eram realizados somente por instruções load/store. A arquitetura possuia ainda cache de dados e instruções separadas.

Algumas das idéias básicas do projeto 801 chegaram a costa oeste dos Estados Unidos no final da década de 70. Na Universidade da California em Berkeley, estas idéias se desenvolveram através de trabalhos de pós-graduação, que produziram o RISC-I, mais tarde seguido pelo RISC-II, e ainda geraram numerosas ferramentas CAD que facilitaram o projeto e implementação.

O processador RISC-I, como o 801, é uma máquina load/store que executa a maioria de suas instruções em um único ciclo. Possui somente 31 instruções, sendo que todas são de 32 bits e possuem praticamente o mesmo formato. Uma característica especial é que 
o RISC-I possui um elevado número de registradores, mais de cem, que são utilizados na forma de uma série de conjuntos sobrepostos entre si (ver §2.6.1). Esta característica, faz com que chamadas de procedimentos (calls), sejam bem menos dispendiosas em termos de tráfego de dados entre processador e memória.

Logo após o início do projeto RISC-I, um outro processador chamado MIPS (Microprocessor without Interlocked Pipeline Stages), começou a ser desenvolvido na Universidade de Stanford [Henn84]. MIPS usava pipeline de instrução, e se baseava em inovações de software para garantir que os recursos de pipeline seriam apropriadamente gerenciados. Em máquinas como o IBM System/360 Model 91, os interestágios com "bolhas" no pipeline são tratados através de hardware especial, durante o tempo execução. Compensando uma menor quantidade de hardware, por um tempo de compilação maior, os pesquisadores de Stanford, foram capazes de explorar o paralelismo interno inerente deste rápido processador.

Estas três máquinas, o 801, RISC-I e MIPS, formaram o núcleo básico das pesquisas precursoras da arquitetura RISC, e dividem entre si um conjunto de características comuns, que definem a arquitetura RISC:

1. Operações em ciclo único, facilitam uma execução rápida de funções simples, implícitas ao campo da instrução, além de possibilitar um tempo de interpretação bastante pequeno.

2. A característica load/store aparece em consequência do desejo por operações em ciclo único.

3. Controle por hardware (hardwired) permite execução rápida de operações em ciclo único. A alternativa de microcodificação leva a um controle muito lento do roteamento, adicionado a um overhead interpretativo.

4. Poucas instruções e poucos modos de endereçamento, possibilitam ao controle da máquina, uma interpretação simples e rápida.

5. Instruções de formato fixo, com uso consistente, facilitam a decodificação, o que novamente acelera o controle da rota de dados. 
6. Maior tempo de compilação, oferece uma oportunidade de se mover complexidades estáticas em tempo execução, para tempo de compilação. Um bom exemplo disto, é o programa reorganizador de pipeline utilizado no MIPS.

As seis características enumeradas acima, podem ser usadas para se eliminar dúvidas quando se compara ou se estuda uma determinada arquitetura. Apesar de alguns aspectos da lista serem discutíveis, eles servem como ponto de partida para nosso trabalho.

\subsection{Suporte para linguagens de alto nível}

Novas arquiteturas devem ser projetadas tendo-se em mente as necessidades de programação das linguagens de alto nível. Entretanto, não importa se a maioria do sistema (linguagem de alto nível) seja implementado por hardware ou por software, desde que o sistema esconda do programador qualquer detalhe de baixo nível da linguagem. Dada uma determinada estrutura, o papel do arquiteto, é construir um sistema com boa relação custo desempenho, decidindo que partes do sistema devem ser implementadas em hardware, e que partes, em software.

Nas pesquisas realizadas em Berkeley, a seleção de linguagens a serem consideradas no projeto RISC, foi de certa forma influenciada pelo ambiente da época; escolheu-se "C" devido a sua larga utilização, e pelo grande número de especialistas nesta linguagem, que trabalhavam então no local [PaSe82].

Dado que é limitado o número de transístores possíveis de serem integrados em uma mesma pastilha, a maior parte do sistema RISC (linguagem de alto nível), é implementada por software, deixando-se para o hardware somente os eventos que consomem muito tempo.

Para se determinar que construções são mais frequentemente utilizadas, e quais delas consomem a maior parte do tempo na média dos programas, examinou-se primeiro a frequência de tipos de variáveis de programas em linguagem de alto nível. Dados coletados para Pascal e C são mostrados na tabela 1.1 .

A observação mais importante da tabela 1.1, foi que constantes inteiras apareciam quase com a mesma frequência de arranjos (arrays) ou estruturas. O que não foi mostrado nesta tabela é que mais de $80 \%$ dos escalares eram variáveis locais, e mais de $90 \%$ dos arrays ou estruturas eram variáveis globais $[\mathrm{PaSe} 82]$. 
Tabela 1.1: Porcentagem dinâmica de operandos em Pascal e C.

\begin{tabular}{|lccccccccc|}
\hline & P1 & P2 & P3 & P4 & C1 & C2 & C3 & C4 & Média \\
\hline constantes inteiras & 14 & 18 & 11 & 20 & 25 & 11 & 29 & 28 & $20 \pm 7$ \\
escalares & 63 & 68 & 46 & 54 & 37 & 45 & 66 & 62 & $55 \pm 11$ \\
arrays/estruturas & 23 & 14 & 43 & 25 & 36 & 43 & 05 & 10 & $25 \pm 14$ \\
\hline
\end{tabular}

P1 COMP - compilador Pascal estilo P-código

P2 MACRO - fase de expansão macro do projeto SCALD I

P3 PRINT - um impressor Pascal

P4 DIFF - programa que acha a diferença entre dois arquivos

C1 PCC - compilador C portável para VAX

C2 CIFPLOT - programa que imprime máscaras VLSI em impressora de pontos

C3 NROFF - formatador de textos

C4 SORT - programa sort do UNIX

Observou-se também a frequência dinâmica relativa de comandos em linguagem de alto nível, para os mesmos programas anteriores. Esta informação não diz quais declarações usam a maioria do tempo, durante a execução de programas típicos. Para responder a esta questão, observou-se o código produzido por versões "típicas" de cada uma das declarações. Uma versão "típica" de cada declaração foi fornecida por Wulf [Wulf81], como parte de seu estudo sobre o desempenho de compiladores.

Neste estudo, utilizou-se compiladores C para um VAX, PDP-11 e 68000 para se determinar o número médio de instruções e referências à memória por declaração. Multiplicandose a frequência de ocorrência de cada declaração, pelo número de instruções de máquina e referências à memória correspondentes, produziu-se a tabela 1.2 , que é ordenada por referências à memória. 
Tabela 1.2: Peso relativo (\%) de declarações em alto nível

(ordenado por referências à memória)

\begin{tabular}{|lcccccc|}
\hline comandos & \multicolumn{2}{c}{ alto nível } & \multicolumn{2}{c|}{ peso } & \multicolumn{2}{c|}{ peso } \\
alto nível & (ocorrência) & \multicolumn{2}{c|}{ (instr. máqu.) } & \multicolumn{2}{c|}{ (ref. mem.) } \\
\hline call/return & $15 \pm 1$ & $12 \pm 5$ & $31 \pm 3$ & $33 \pm 14$ & $44 \pm 4$ & $45 \pm 19$ \\
loops & $5 \pm 0$ & $3 \pm 1$ & $42 \pm 3$ & $32 \pm 6$ & $33 \pm 2$ & $26 \pm 5$ \\
assign & $45 \pm 5$ & $38 \pm 15$ & $13 \pm 2$ & $13 \pm 5$ & $14 \pm 2$ & $15 \pm 6$ \\
if & $29 \pm 8$ & $43 \pm 17$ & $11 \pm 3$ & $21 \pm 8$ & $7 \pm 2$ & $13 \pm 5$ \\
with & $5 \pm 5$ & - & $1 \pm 0$ & - & $1 \pm 0$ & - \\
case & $1 \pm 1$ & $<1 \pm 1$ & $1 \pm 1$ & $1 \pm 1$ & $1 \pm 1$ & $1 \pm 1$ \\
go to & - & $3 \pm 1$ & - & $0 \pm 0$ & - & $0 \pm 0$ \\
\hline
\end{tabular}

Os dados da tabela 1.2 sugerem que as operações call/return de procedimentos, em programas em alto nível, são as que mais consomem tempo. Estes resultados confirmam os estudos de Lunde e Witchmann [PaSe82]. As estatísticas em operandos, encontradas na tabela 1.1 enfatizam a importância de variáveis locais e constantes. A arquitetura RISC suporta linguagens de alto nível, melhorando o desempenho das atividades que mais consomem tempo em um programa típico em alto nível, ao invés de tornar a arquitetura "próxima" de uma determinada linguagem de alto nível. Assim em RISC, tenta-se manusear variáveis locais, constantes e chamadas de procedimentos de forma eficiente, deixando operações menos frequentes para sequências de instruções ou subrotinas. 


\section{Capítulo 2}

\section{Natureza da arquitetura RISC}

Neste capítulo, as características básicas da arquitetura RISC, tais como pipeline, conjunto de instruções, banco de registradores, serão discutidas de forma global, baseando-se nas arquiteturas RISC I e II de Berkeley e na simulada neste trabalho. É também discutida uma importante característica adotada em nossa arquitetura, que não aparecia nas arquiteturas de Berkeley [PaSe81] [PaSe82] [Kate84], Stanford(MIPS) [Henn84] e IBM801 [Radi83]. Um seção final descreve o esquema de memória cache empregada nesta arquitetura.

\subsection{Conjunto de Instruções}

Com o intuito de permitir um rápido acesso à operandos, a arquitetura RISC é orientada a registrador, característica consequente das simulações mostradas nas tabelas 1.1 e 1.2 $(\S 1.2)$.

Operações realizadas sobre operandos na memória, são decompostas em subtarefas: primeiro traz-se os operandos para registradores, depois realiza-se a operação, e por último leva-se o resultado de volta para memória. Esta decomposição não acarreta diminuição no desempenho, desde que uma apropriada canalização de tarefas (pipeline), seja utilizada. Consegue-se com isto uma simplificação no conjunto de instruções e em sua implementação.

Para simplicidade e eficiência do mecanismo de busca e sequencialização de instruções, todas as instruções em um processador RISC possuem tamanho fixo de uma palavra $($ word $)$. 
Cada instrução possui, além do tamanho fixo, formato fixo com campos em lugares previamente estabelecidos pela arquitetura, possibilitando decodificação simples e rápida.

As operações realizadas pelas instruções, ocupam toda a estrutura por onde os dados irão passar, assegurando um rápido roteamento dos dados e uma alta utilização dos recursos disponíveis, permitindo assim temporização simples e homogênea.

Por acreditar-se que um espaço virtual de memória de 4 Gbytes será suficiente durante muitos anos, RISC é fundamentalmente uma arquitetura de 32 bits. A memória suporta dados tipo caracter (byte), meia-palavra (half-word $=2$ bytes) e palavra (word $=4$ bytes), que são todos convertidos para palavra quando movidos para registradores. Isto permite simplicidade, mantendo-se total operacionalidade com inteiros e caracteres, pois quem se preocupa com o alinhamento de dados é a arquitetura.

\subsection{Organização Orientada a Registrador}

Um computador gasta $70 \%$ de seu tempo realizando acessos a operandos, e os $30 \%$ restantes em operações: de fato para cada operação, necessita-se uma ou duas fontes de operandos, e o resultado é colocado em outro operando. Se considerarmos uma alta frequência de transferências do tipo A-recebe-B [Tane78], onde existe referências a operandos mas não existe operação, notamos o quão importante é para um computador possuir um rápido acesso a operandos.

O meio físico de armazenamento de dados de acesso mais rápido, é o conjunto de registradores da UCP, devido ao fato de ser fisicamente pequeno, estar na mesma pastilha que a UCP e necessitar um número reduzido de linhas de endereçamento, o que permite decodificação rápida.

Por estas razões, em arquitetura RISC, mantêm-se o quanto mais possível operandos em registradores. Operações são realizadas por instruções registrador-registrador de três operandos:

$$
R_{d} \leftarrow R_{s 1 \text { op }} S_{2}
$$

Como mostrado no capítulo anterior, constantes são de grande importância, respondendo por 15 a $20 \%$ dos operandos utilizados. Assim, na instrução genérica acima, o 
segundo operando fonte $S_{2}$ pode ser um registrador $R_{s 2}$ ou uma constante imm. Um dos registradores, normalmente $R_{0}$, sempre contém a constante 0 (zero). É permitido escrever-se neste registrador, mas seu valor não será alterado (está lógicamente ligado a zero via hardware). Somente os flags de condição de código (CCs) serão afetados, caso se queira. Operações disponíveis incluem:

- adição inteira (com ou sem carry)

- subtração inteira (com ou sem carry)

- subtração inteira inversa $\left(-R_{s 1}+S_{2}\right)$ (com ou sem carry)

- operações booleanas bit a bit E, OU, OU EXCLUSIVO

- deslocamento (shift) lógico à esquerda, lógico à direita ou aritmético à direita (todos por uma quantia arbitrária)

Todas as instruções podem habilitar 4 condições de código.

Instruções $a d d / s u b$ são de 32 bits com sinal e com operandos em complemento de dois. Existem também condições de desvio (p.e. desvie se igual a zero) que agem sobre operandos de 32 bits sem sinal.

Versões de $a d d / s u b$ realizadas com carry (vai um) são usadas para operações com operandos maiores que 32 bits.

Instruções shift (deslocamento), realizam o deslocamento de $R_{s 1}$ por uma quantia especificada pelos 5 bits menos significativos de $S_{2}$.

Shifts lógicos à direita preenchem posições deslocadas com zero, e shifts aritméticos extendem o sinal.

Rotações e shift aritmético à esquerda não são incluídos pois eles não existem em linguagem de alto nível.

Muitas instruções de uso frequente não foram incluídas, sempre que se pudesse sintetizá-las utilizando-se outras instruções; por exemplo, instruções move não são incluídas, pois é possível sintetizá-las usando-se instruções add, já que ambas possuem o mesmo tempo de execução. Algumas possibilidades são ilustradas na tabela 2.1: 
Tabela 2.1: Sintetizando instruções em RISC

\begin{tabular}{|ll|}
\hline Instrução & Método para sintetiza-la \\
\hline move & $R_{d} \leftarrow R_{s}+R_{0} \equiv 0$ \\
incremento, decremento & ADD com constante imm 1,-1 \\
complemento & $R_{0}-R_{s}$ \\
negação (NOT) & $R_{s}$ XOR $(-1)$ \\
limpar (clear) & $R_{d} \leftarrow R_{0}+R_{0}$ \\
compara, testa & usa-se $R_{0}$ como $R_{d}$, e habilita-se \\
& condições de código \\
\hline
\end{tabular}

\subsection{Acesso à memória e modos de endereçamento}

No padrão RISC I e II de Berkeley, todas as instruções aritméticas, lógicas, e shifts são realizadas em registradores.

Somente instruções load/store podem ter acesso a operandos em memória, e movelos entre registradores e memória. Isto simplifica o roteamento dos dados, a unidade de controle, o formato de instrução, e ainda o manuseio de interrupções causada por demanda de página. Instruções load/store possuem modo de endereçamento simples:

$$
R_{d} \leftrightarrow M\left[R_{s 1}+R_{s 2}\right]^{1}
$$

Com isto podemos sintetizar muitos outros modos de endereçamento, como mostra a tabela 2.2 .

A memória é endereçada byte a byte. Meia-palavra ( 2 bytes) são alinhados de dois em dois bytes, e palavras, de quatro em quatro. Quando transferidos para registradores, bytes e meia-palavra são alinhados à direita através de instruções apropriadas.

Instruções load/store possuem versões diferentes para palavra, meia-palavra e byte; além disso, loads possuem versões para dados com ou sem sinal, ou seja, extendem o sinal ou preenchem com zeros quando se trata de byte ou meia-palavra.

\footnotetext{
${ }^{1} \mathrm{M}$ é posição de memória apontada por $R_{s 1}+R_{s 2}$
} 
Tabela 2.2: Sintetizando modos de endereçamento em RISC

\begin{tabular}{|lll|}
\hline Modo & uso em ling. alto nível & sintet. em RISC \\
\hline Absoluto(Diret.) & escalar global & $\begin{array}{l}M\left[R_{B}+i m m\right] \\
(\text { com } \pm 4 \mathrm{~K} \text { bytes }\end{array}$ \\
& & offset da base $\left.R_{B}\right)$ \\
& & $M\left[R_{p}+R_{0}\right]$ \\
Reg. Indireto & ponteiro def. $(* p)$ & $M\left[R_{p}+\right.$ campo_off $]$ \\
Indexado & campo da estr. $(\mathrm{p} \rightarrow$ campo) \\
Indexado & arr. linear de bytes $(\mathrm{a}[\mathrm{i}])$ & $\begin{array}{l}M\left[R_{a}+R_{i}\right] \\
\text { (assume } R_{a} \text { aponta }\end{array}$ \\
& & para base de a $[])$. \\
\hline
\end{tabular}

Com relação a instruções de transferência de controle (jump, call, return), existe um modo de endereçamento adicional, o PC-relativo onde o endereço efetivo é dado por:

$$
\text { endereço_efetivo }=P C+i m m
$$

onde, PC é o contador de programa e imm é uma constante de 19 bits.

Este modo foi adicionado pois o contador de programa (PC) não faz parte do banco de registradores.

\subsection{Transferência de controle com atraso}

Desde o inicio de pesquisas em arquiteturas RISC [Kate84], sempre teve-se em mente o pipeline de instruções, onde sobrepõem-se busca de instrução e execução. Neste trabalho, a fase de armazenamento do resultado também é sobreposta.

O pipeline pode as vezes ser rompido por uma instrução de transferência de controle, como desvios (branchs) condicionais e incondicionais, chamadas de subrotinas e seu retorno.

A figura 2.1 mostra a busca da instrução de transferência de controle $I_{1}$, que é em seguida executada. Durante sua execução, é computado um endereço para um possível desvio (branch) e então avaliada a condição de desvio. Simultâneamente, a instrução subsequente $I_{2}$ esta sendo buscada. Caso ocorra o desvio é necessário que se busque uma nova instrução $I_{3}$, desperdiçando-se assim um ciclo do pipeline onde foi buscado $I_{2}$.

\footnotetext{
${ }^{2}$ só é possível offset de $\pm 4 \mathrm{~K}$ bytes pois $i m m$ possui 13 bits
} 
Para resolver este problema, a arquitetura RISC se vale de uma antiga técnica usada no MANIAC-I [PaSe82] conhecida como delayed-branch (desvio atrasado). Neste esquema, a transferência de controle para $I_{3}$ só ocorre após a execução de $I_{2}$, quer ocorra ou não o desvio, $I_{2}$ será executada. Assim uma instrução imediatamente após jump/call/return será sempre executada, antes da transferência de controle. Normalmente o compilador coloca um NOP(não operação) neste lugar, e o otimizador tenta mover uma instrução apropriada para este local. Isto sempre pode ser feito quando a transferência não depende desta instrução.

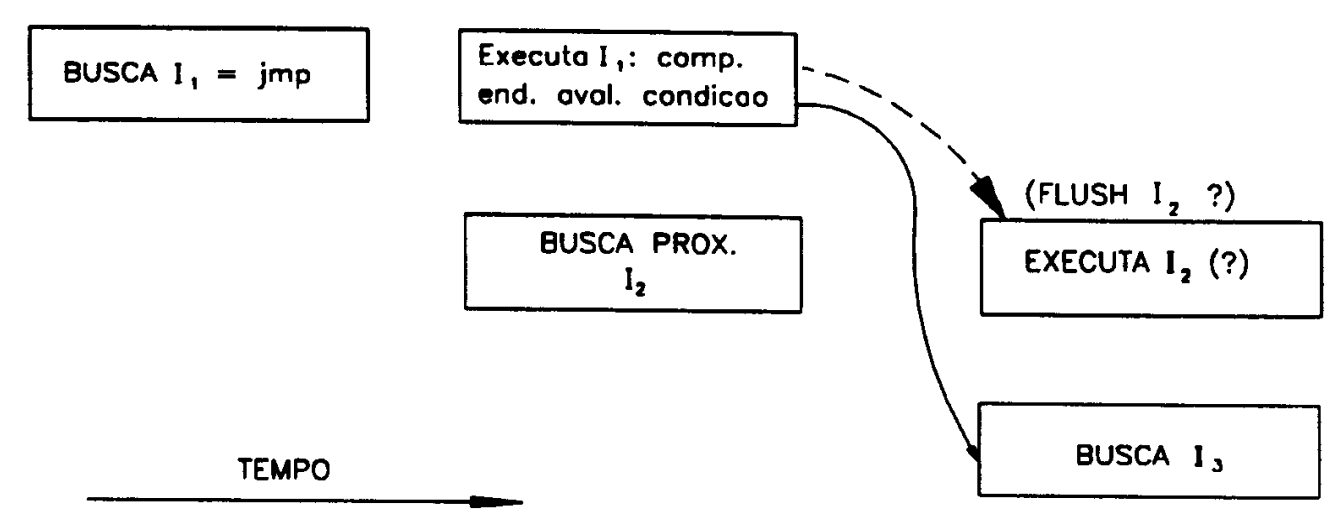

Figura 2.1: Esquema de desvio atrasado (delayed branch)

Estudos a este respeito [Kate84] têm mostrado que otimizadores conseguem remover em torno de $90 \%$ dos NOPs alocados após transferências incondicionais, e algo em torno de 40 a $60 \%$ no caso de transferências condicionais. Instruções de transferência de controle normalmente representam $20 \%$ de todas instruções. Assim, enquanto num pipeline convencional se perde $20 \%$ dos ciclos, com um código RISC otimizado, perde-se apenas 6\%. Estes números concordam com os números colhidos por John Cocke no IBM-801 [Kate84]. 


\subsection{Instrução de formato fixo}

A complexidade de certos processadores se deve em parte, ao trabalho de decodificação de instruções, ou seja, a tarefa de extrair-se os vários campos dos variados formatos de instrução.

A arquitetura RISC, ao contrário da CISC, possue um simples formato de instrução, com campos em posições fixas. Isto permite um circuito decodificador muito simples e extremamente rápido.

Todas as instruções RISC são de 32 bits. A figura 2.2 mostra o formato de instrução empregado neste trabalho, formato este idêntico ao da arquitetura RISC II de Berkeley [Kate84]. Os registradores visíveis ao programador em linguagem de máquina são 32 , e assim necessitamos 5 bits para endereçar registradores (operandos). Existe espaço para 128 códigos de operação (op-codes), embora este trabalho utilize somente 30.

Se o bit (SCC) estiver ligado (nível lógico 1) as condições de código serão afetadas, dependendo do resultado $\left(R_{d}\right)$ da instrução.

O campo DEST pode especificar o registrador destino $\left(R_{d}\right)$, ou a condição de transferência de controle utilizando-se os 4 bits menos significativos deste campo.

O formato curto-imediato é usado para todas as instruções registrador-registrador, para instruções load/store e para instruções de transferência de controle. O campo FONTE2 consiste de 14 bits, e neste caso o bit mais significativo deste campo diz se o campo deve ser interpretado como $R_{S 2}$ ou como uma constante imediata de 13 bits em complemento de dois. No primeiro caso, os oito bits restantes são descartados.

O formato longo-imediato é usado por instruções PC-relativo, e neste caso o deslocamento pode ser de 19 bits em complemento de dois. Este formato é também usado pela instrução load-high, que pega os bits do campo e coloca-os nas 19 posições mais significativas de $R_{d}$, preenchendo com zero as posições menos significativas. Esta instrução é usada em conjunto com uma de 13 bits imediatos para se carregar uma constante de 32 bits em um registrador. 


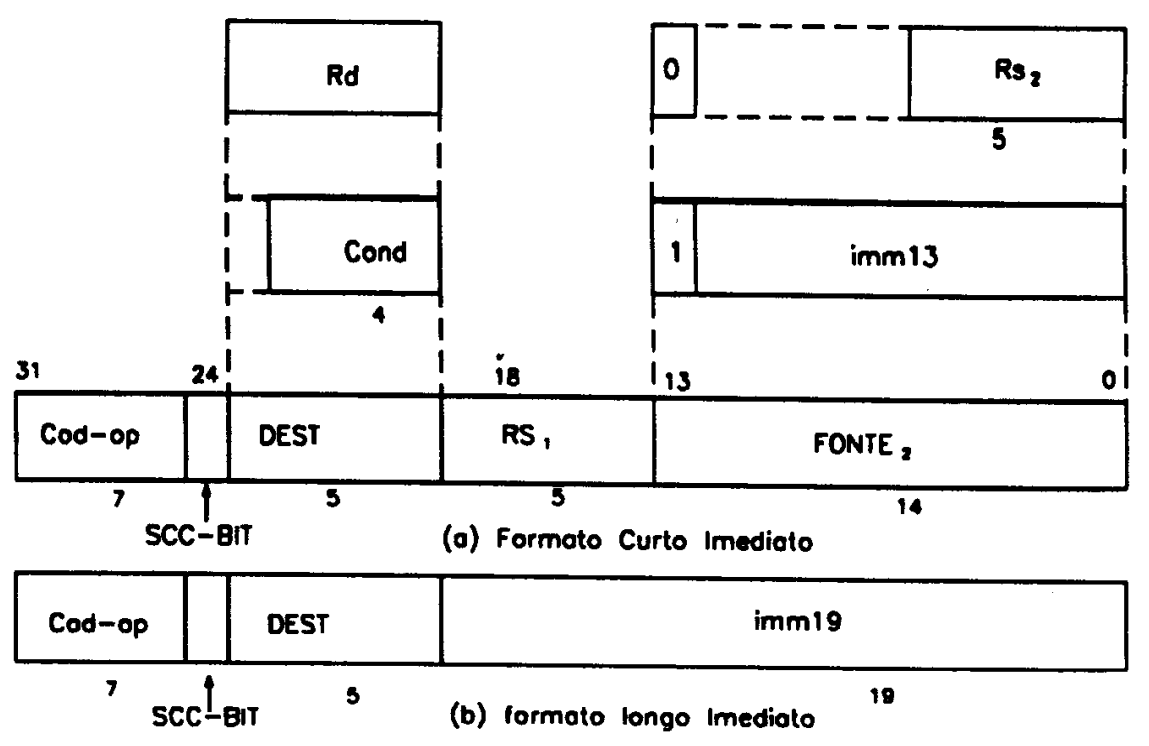

Figura 2.2: Formatos de instrução

\subsection{Banco de registradores}

Com o intuito de manter operandos o mais possível em registradores, permitindo um rápido acesso a eles, adotamos nesta arquitetura o mesmo esquema das arquiteturas de Berkeley e da UCP SPARC [SunM88]. Investigações no uso de linguagens de alto nível [TaSe83], sugerem que as operações call são as que consomem a maior parte do tempo de execução de um programa.

Potencialmente, programas RISC podem ter mais operações call, pois instruções complexas encontradas em máquinas CISC, são subrotinas em RISC. Assim as instruções call devem ser executadas tão rápidamente quanto possível.

O uso de procedimentos envolve dois grupos de operações que consomem tempo: salvar ou restaurar registradores a cada instrução call ou return. Além de se realizar este tipo de operação com um consumo de tempo muito pequeno, se comparado a outras máquinas, a arquitetura RISC possui suporte arquitetural para escalares locais, característica há muito tempo prevista por Baskett e Sites (referenciado em [Stal88]). 


\subsubsection{Janelas de registradores entrelaçadas}

A figura 2.3 mostra a organização de um banco de registradores de formato fixo, entrelaçado (janelas de registradores adjacentes, possuem registradores comuns entre si). Nem todos os registradores existentes, são visíveis ao programador em linguagem de máquina a cada instante. $\mathrm{O}$ conjunto de registradores visíveis a cada instante é chamado "janela corrente" [Kate84]. A janela é selecionada através de um número associado a ela, fornecido pelo registrador de estado da UCP, que é colocado na entrada do decodificador; um registrador desta janela é então selecionado através de um endereço fornecido pela instrução.

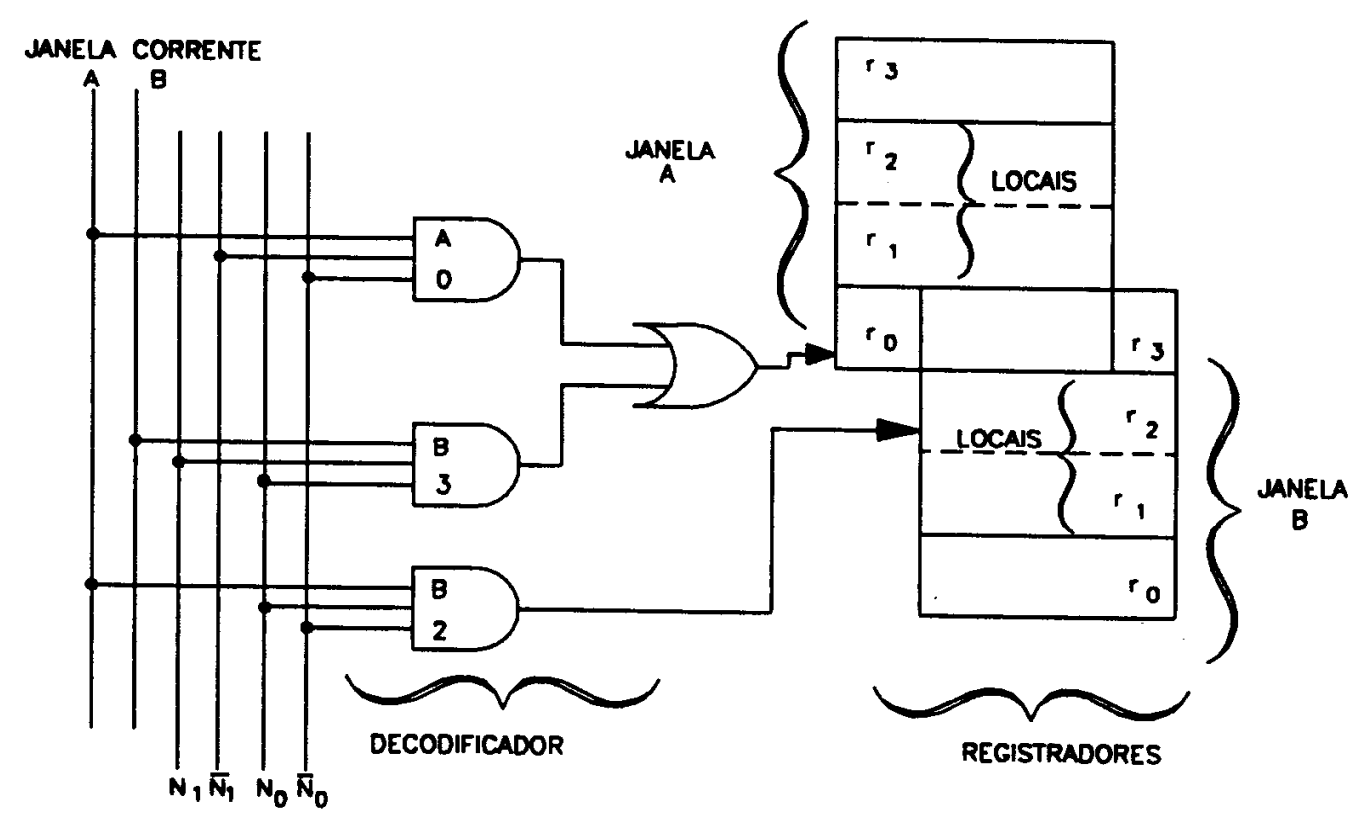

Figura 2.3: Janelas de tamanho fixo entrelaçadas

Alguns registradores pertencem a duas janelas diferentes, mas possuem numeração diferente em cada uma delas; estes são chamados registradores "sobrepostos" ou "entrelaçados" enquanto que, aqueles pertencentes a uma única janela são chamados de "lo- 
cais". Além destes, existem ainda os registradores "globais", que podem ser endereçados a qualquer instante, possuindo sempre o mesmo número.

Toda vez que uma operação call é executada, o número da janela muda. O compilador deve alocar escalares locais de procedimentos em registradores locais, de tal forma que uma nova ativação desta janela (chamada ou retorno a este procedimento) possuirá acesso a estes escalares sem a necessidade de uma nova alocação. Quando não existem registradores suficientes na UCP, variáveis locais tanto escalares como não escalares, são alocadas em uma pilha na memória principal.

As janelas de registradores são organizadas em forma de pilha. Procedimentos adjacentes (pai $\leftrightarrow$ filho) são alocados em janelas adjacentes. O compilador aloca os parâmetros a serem passados (de-para) entre os procedimentos, nos registradores comuns às duas janelas (região sobreposta). Estes registradores possuem numeração diferente nestas duas janelas; esta diferença serve para distinguir registradores de "entrada" de registradores de "saída" de argumentos. Por exemplo, na figura 2.3 r0 é registrador de "saída" na janela A, se tornando $\mathbf{r} 3$ na janela $\mathbf{B}$ onde é registrador de "entrada" de argumento.

Desta forma, pode-se passar argumentos via registrador sem que haja transporte de dados. Um dos registradores da região sobreposta é usado para salvar-se o endereço de retorno (contador de programa da instrução subsequente à instrução call). Também, quando é necessario retornar-se um valor ao procedimento "chamante", usa-se estes mesmos registradores.

Com este esquema, as regiões de registradores locais, de entrada e de saída, possuem tamanho fixo, o que permite uma simples e rápida decodificação (ver fig. 2.3). Neste trabalho adotamos um esquema idêntico ao RISC II de Berkeley, que possui 10 registradores globais, 10 registradores locais por cada janela, 6 registradores de "saída", e 6 de "entrada" de argumentos. Estes números derivam dos resultados obtidos por Yuval Tamir em [TaSe83].

\subsubsection{Organização circular das janelas de registradores}

A figura 2.4 ilustra a organização circular das janelas de registradores para 6 janelas. A arquitetura proposta neste trabalho usa 8 janelas, seguindo conclusões obtidas por Yuval Tamir em [TaSe83] (melhores números para disposição dos registradores dentro de cada 
janela, melhor número de janelas e melhor número de janelas a serem salvas/restauradas na ocorrência de transbordo/esvaziamento (overflow/underflow)).

Dois ponteiros são utilizados para apontar as janelas vazias e ocupadas. O ponteiro para a janela corrente, CWP (current window pointer), aponta para a janela ativa, ou seja, aquela que esta em uso pelo procedimento corrente.

O SWP (saved window pointer), identifica a última janela que foi salva na memória. No exemplo da figura 2.4, quatro janelas estão em uso. Pode-se notar que os registradores de "saída" de argumentos de uma determinada janela, se tornam registradores de "entrada" da próxima janela.

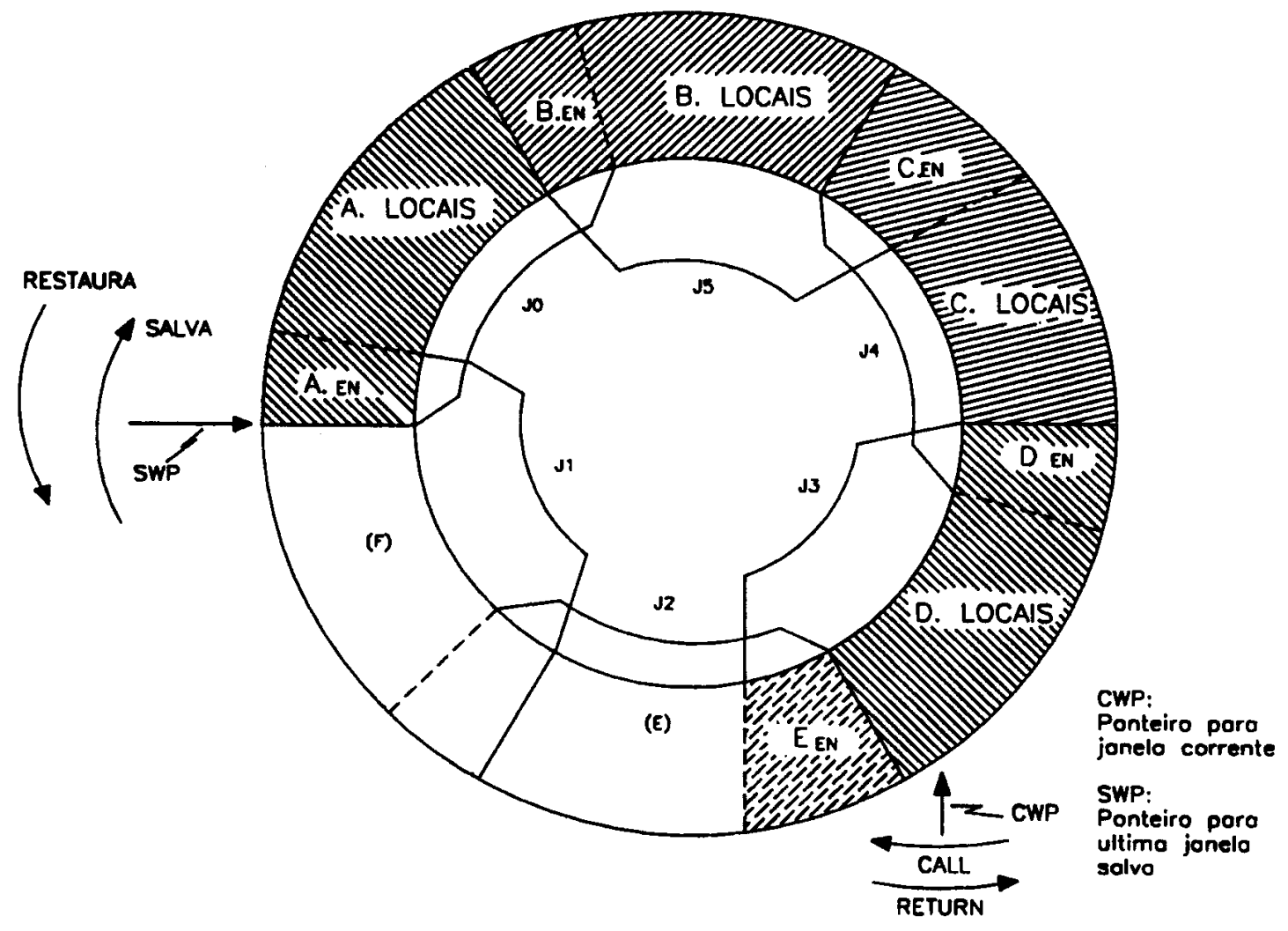

Figura 2.4: Organização circular das janelas de registradores 
Argumentos passados por valor são diretamente colocados na região sobreposta e passados via registrador. No caso de argumentos passados por referência, os registradores sobrepostos irão conter ponteiros para estes argumentos.

Se o procedimento D na figura 2.4 necessitar realizar um call para o procedimento $E$, ele escreverá os argumentos a serem passados nos registradores de "saída" (região sobreposta de j3 com j2), e então executará a instrução call. Uma instrução call move CWP para outra janela em uma direção (no nosso exemplo, decremento, módulo 6), ao passo que uma instrução return move CWP em sentido contrário. Se o procedimento E decidir realizar um call para o procedimento $F$, a instrução não poderá ser realizada instantaneamente devido ao estado de janela ocupada. A razão é que $\mathrm{F}$ não poderá escrever em seus registradores de "saída" de argumentos, sem que se destrua os argumentos de entrada $A_{\text {in }}$ de A. Além disso, alguns registradores devem estar sempre sempre livres para uso de interrupções.

Assim quando o procedimento E executa uma instrução call, dizemos que houve um transbordo (overflow) do banco de registradores. Neste caso é gerada uma interrupção que faz com que a instrução call pare. O critério para geração desta interrupção em transbordo é : quando uma instruçâo call tenta modificar CWP de forma que ele se torne igual a $S W P$ [Kate84].

A rotina de interrupção passa o controle para uma rotina que manuseia transbordo, salvando uma ou mais janelas de registradores na memória. A melhor estratégia encontrada por Tamir e Séquin [TaSe83], é salvar apenas uma janela a cada transbordo.

Considerações similares também levam a um critério idêntico para geração de interrupção para esvaziamento (underflow): quando uma instrução return tenta modificar CWP de forma que ele se torne igual a SWP [Kate84]. Note que um simples circuito coincidência é suficiente para detectar transbordo e esvaziamento.

Portanto um banco de registradores com $N$ janelas pode manipular no máximo $N-1$ janelas ativas. Interrupções modificam CWP da mesma maneira que instruções call. Então, rotinas de interrupção são executadas em uma janela onde os registradores garantidamente estão livres, e não é permitido o aninhamento de procedimentos antes de se verificar a disponibilidade de outras janelas. 


\subsection{Pipeline}

Um dos métodos mais tradicionais de melhorar o desempenho de um processador, é o uso do pipeline de instrução. Com a simplicidade da arquitetura RISC, tornou-se possível um uso mais efetivo deste tipo de pipeline.

\subsubsection{Modelo de pipeline empregado em RISC}

A maioria das instuções RISC podem ser executadas gastando-se a mesma quantidade de tempo, a partir do seguinte modelo de execução:

- buscar uma instrução

- ler $R_{S 1}$ e $R_{S 2}$ (ou ler PC ou imm)

- realizar uma operação aritmética, lógica ou deslocamento em S1 ou S2

- escrever o resultado em $R_{d}$, ou usar um endereço efetivo para um acesso à memória

A arquitetura IBM-801 [Radi83] [Patt85], assume que cada parte gaste a mesma quantia de tempo, e assim usa um pipeline de 4 estágios. Em Berkeley, assumiu-se que o tempo de busca de instrução era igual a soma do tempo de leitura dos registradores mais o tempo de execução da operação, e assim adotaram um pipeline de 3 estágios como mostrado na figura 2.5. Este trabalho adota um modelo de 3 estágios, similar ao de Berkeley.

Para evitar a dependência de dados entre instruções subsequentes (fig 2.6), o pipeline do RISC II usa a técnica de adiantamento interno de resultado [Patt85][Kate84]. Dois comparadores de equalidade detectam as condições $R_{S 1, I 2}=R_{d, I 1}$ ou $R_{S 2, I 2}=R_{d, I 1}$, para verificar se um dos operandos de uma determinada instrução é igual ao resultado da instrução anterior, que ainda se encontra no pipeline. Quando ocorrer igualdade, o resultado da operação $I_{1}$ é automaticamente adiantado de uma latch $h^{3}$ temporária para uso de $I_{2}$.

\footnotetext{
${ }^{3}$ explicado com detalhes no cap. 3
} 


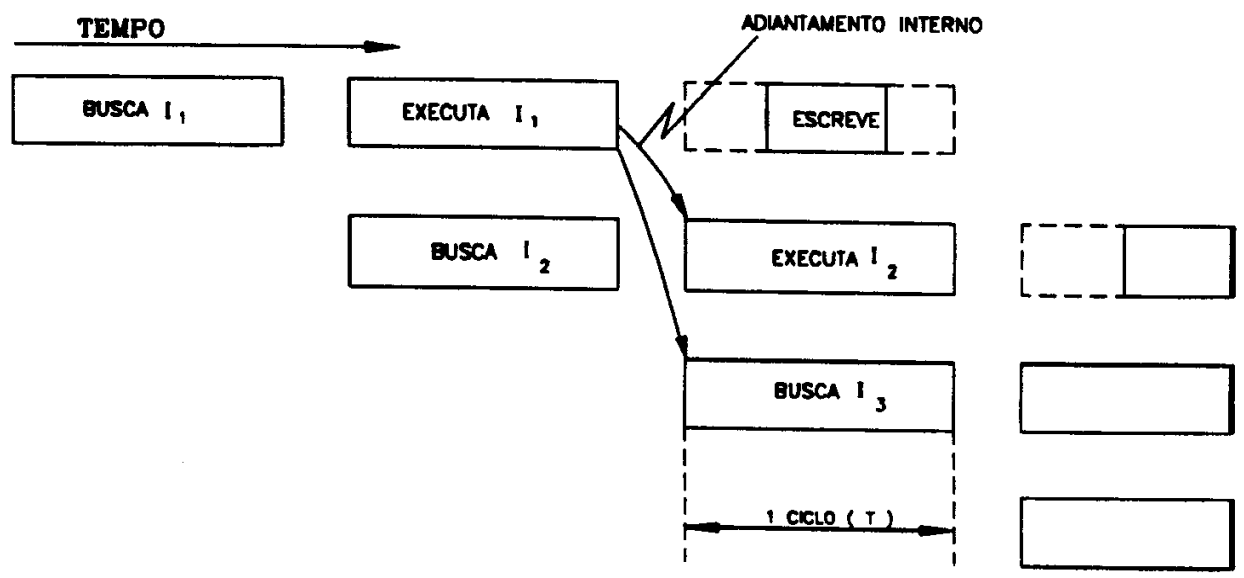

Figura 2.5: Pipeline do RISC II

\subsubsection{Suspensão do pipeline durante acesso à memória}

As arquiteturas RISC I e II de Berkeley, possuem um único porto de comunicação entre a UCP e a memória, e esta não usa pipeline. Isto significa que somente um acesso à memória pode ser realizado a cada instante. Em decorrência disto, quando uma instrução load ou store está sendo realizada, o resto do pipeline é temporariamente suspenso (fig 2.7(a)) pois não é possível realizar-se a busca da próxima instrução simultâneamente.

Como sugerido por Katevenis em sua tese de doutorado [Kate84]( $§ 6.3)$, adotamos neste trabalho uma UCP com com cache de dados e cache de instrução separadas, integradas na mesma pastilha, já que hoje dispomos de tecnologia que permite um milhão de trànsistores por pastilha.

Assim temos uma arquitetura Harvard-RISC que se caracteriza por possuir dois portos diferentes de comunicação com a memória, um para dados e outro, para instruções. Neste caso estudaremos pipelines que não são suspensos durante referências à memória (fig 2.7(b)).

Com duplo porto de comunicação, o acesso a dados em instruções load e store pode ocorrer em paralelo com a computação da próxima instrução (execução e busca). Para instruções store, isto não causa problema de dependência de dados. Entretanto para 


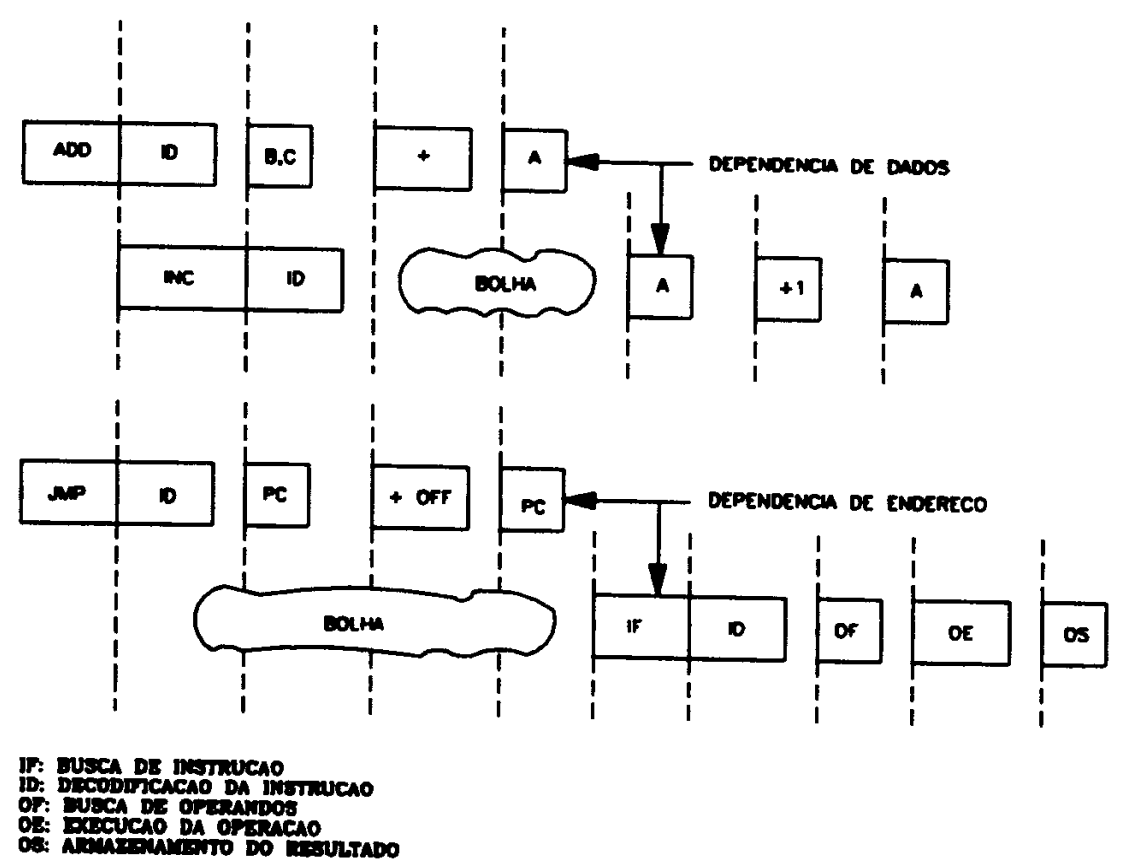

Figura 2.6: Dependência de dado e endereço no pipeline 
instruções load, o problema existe.

O ciclo de computação da instrução imediatamente seguinte a uma instrução load não deve depender do valor que está sendo carregado. Esta condição necessita ser verificada pelo compilador, que deve inserir um NOP (não operação) se nenhum trabalho útil puder ser realizado imediatamente após a instrução load. Alternativamente, esta condição poderia ser detectada por hardware, e então o pipeline seria suspenso enquanto o dado não chegasse da memória. Se o banco de registradores puder manusear somente uma escrita por ciclo, como no caso do RISC II, um estágio dummy deverá ser inserido em todas as instruções no local onde loads realizam seu acesso à memória (fig 2.7(b)).

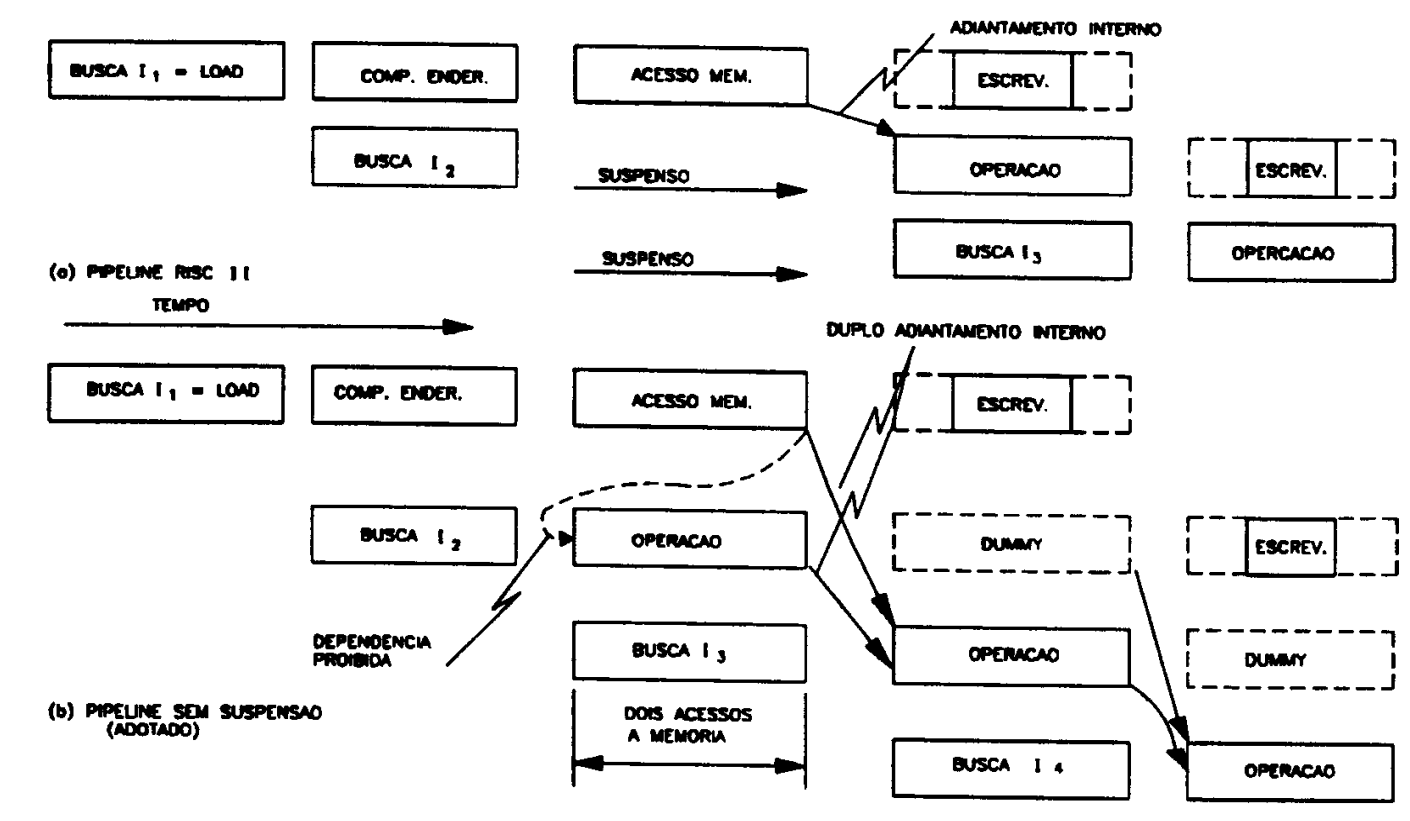

Figura 2.7: Suspensão do pipeline durante acesso à memória

Um esquema avançado de pipeline, usando porta dupla para escrita nos registradores, certamente aumentaria a velocidade de execução de instruções load/store, mas qual seria o impacto global disto com relação ao desempenho e, quão frequente são instruções load seguidas de computação que não depende delas ? Numa discussão informal com John 
Cocke do IBM Research Center, Katevenis [Kate84] obteve os seguintes números com relação ao projeto 801: $16 \%$ de todas instruções executadas (no 801) eram loads seguidos de computação independente, enquanto que $9 \%$ eram loads seguidos por computação dependente. O IBM 801 possui um pipeline similar ao da figura 2.7(b), mas com duplo porto de escrita e sem estágios dummy.

Cocke não forneceu números com relação a instruções store, mas usualmente sua frequência está em torno de $10 \%$. Estes números mostram que aproximadamente um quarto de todos os ciclos podem ser salvos no 801, com a não suspensão do pipeline durante um acesso à memória.

Estes números apontados por John Cocke se referem a um processador (801) sem um esquema de janelas de registradores. Tal processador necessita acessar variáveis em memória, ou salvar/restaurar registradores com mais frequência que um processador que possua janelas de registradores.

Programas RISC executam poucas instruções load/store. Em três programas rodados (cap. 1), obteve-se para instruções load, de todas instruções executadas, $17 \%, 13 \%$ e $15 \%$ respectivamente [PaSe81]. As correspondentes porcentagens para instruções store foram $1 \%, 1 \%$ e $9 \%$. Em RISC, espera-se que as instruções seguintes a loads devam depender delas mais frequentemente que em outras arquiteturas pois, a restauração de múltiplos registradores a partir da memória em retornos de procedimentos, é bem menos freqüente.

Portanto a porcentagem de ciclos de execução em RISC que podem ser salvos, permitindo-se busca de instrução e acesso à dados em memória simultâneamente, podem ser estimados em $10 \%$.

\subsection{Memória Cache}

Memórias cache [Smit82] são utilizadas em CPUs de média e alta velocidade para manter temporariamente porções do conteúdo da memória principal que estão (ou acredita-se que estão) correntemente em uso. Desde que, usando-se memória cache, referencia-se instruções e dados com um tempo de 10 a $25 \%$ do tempo requerido para se acessar a memória principal, memórias cache permitem um aumento substancial na velocidade da máquina, se a frequência de acessos à cache for alto. 
Para um perfeito funcionamento, memórias cache devem ser projetadas e implementadas de forma bastante cuidadosa.

\subsubsection{Cache do processador Clipper(Fairchild)}

Aqui é mostrado como funciona a cache do processador Clipper [Clip87], que é um processador híbrido (RISC-CISC), que consiste de duas caches de $4 \mathrm{kbytes} \mathrm{cada,} \mathrm{sendo} \mathrm{uma}$ para instruções e outra para dados.

Define-se hit rate como razão entre o número de acessos à cache e o número de vezes em que o dado é encontrado nela.

$O$ hit rate é função de quatro fatores:

- o tamanho da cache em bytes

- número de bytes por linha

- grau de set-associativity

- localidade do programa

O tamanho da linha é o número de bytes que são trazidos para dentro da cache, quando uma referência à memória principal é feita. O Clipper usa linha de 16 bytes, o que significa que quando um miss (quando o dado não foi encontrado na cache) ocorre, 16 bytes são atualizados. Estudos realizados em Berkeley [Smit82], revelam que linha de 16 bytes é um bom tamanho. Cada cache possui 256 linhas.

O grau de set-associativity da cache determina quanta flexibilidade a cache possui em escolher qual linha substituir na ocorrência de um miss. A figura 2.8 ilustra a cache do Clipper, que funciona no esquema conhecido como two way set associativity.

$\mathrm{Na}$ cache do Clipper, ilustrada na figura 2.9, cada set possui 2 linhas de 16 bytes cada, e há 128 sets. Os sets do lado esquerdo são chamados de compartimento $\mathrm{W}$, e os do lado direito de compartimento $X$. Há um total de 2 kbytes em cada compartimento, sendo a memória física dividida em páginas de $4 \mathrm{k}$ bytes. Em cada página, uma locação é mapeada numa única locação em um dos compartimentos. Consequentemente, muitas locações da memória principal são mapeadas num mesmo par de locações da cache. Na primeira 


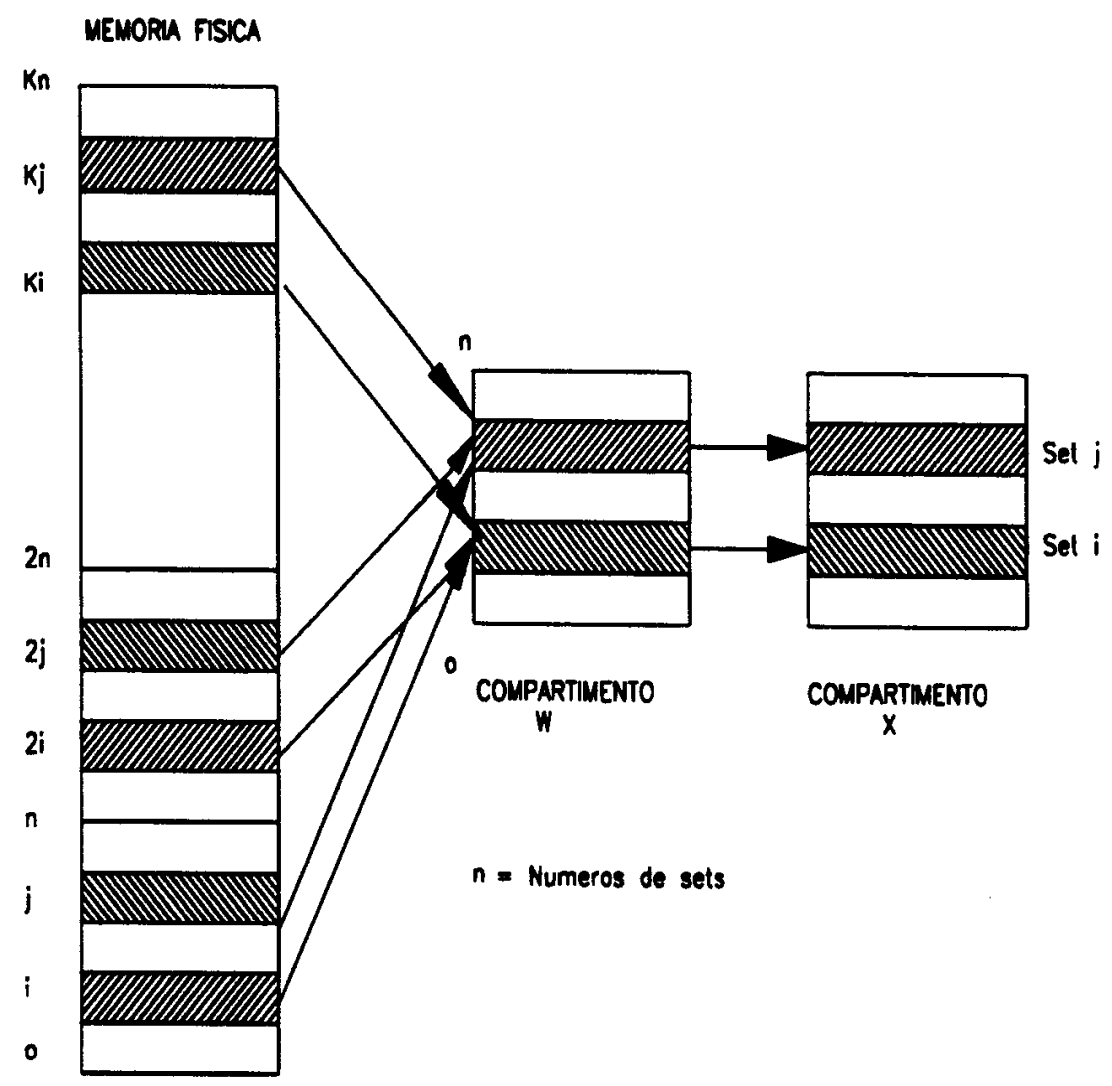

Figura 2.8: Set Associativity 
vez que a memória principal é acessada, 16 bytes são buscados e armazenados em uma linha do compartimento $W$. Se um novo acesso a memória principal requerer a mesma locação na cache, será então utilizado o compartimento X. Se os dois compartimentos de um mesmo set estiverem cheios, a cache irá atualizar aquele compartimento menos recentemente utilizado (técnica conhecida como LRU-least recently used), usando o bit $\mathrm{U}$. $\mathrm{O}$ bit $\mathrm{U}$ é automaticamente habilitado quando o compartimento $\mathrm{W}$ é acessado, e desabilitado quando o $\mathrm{X}$ é acessado.

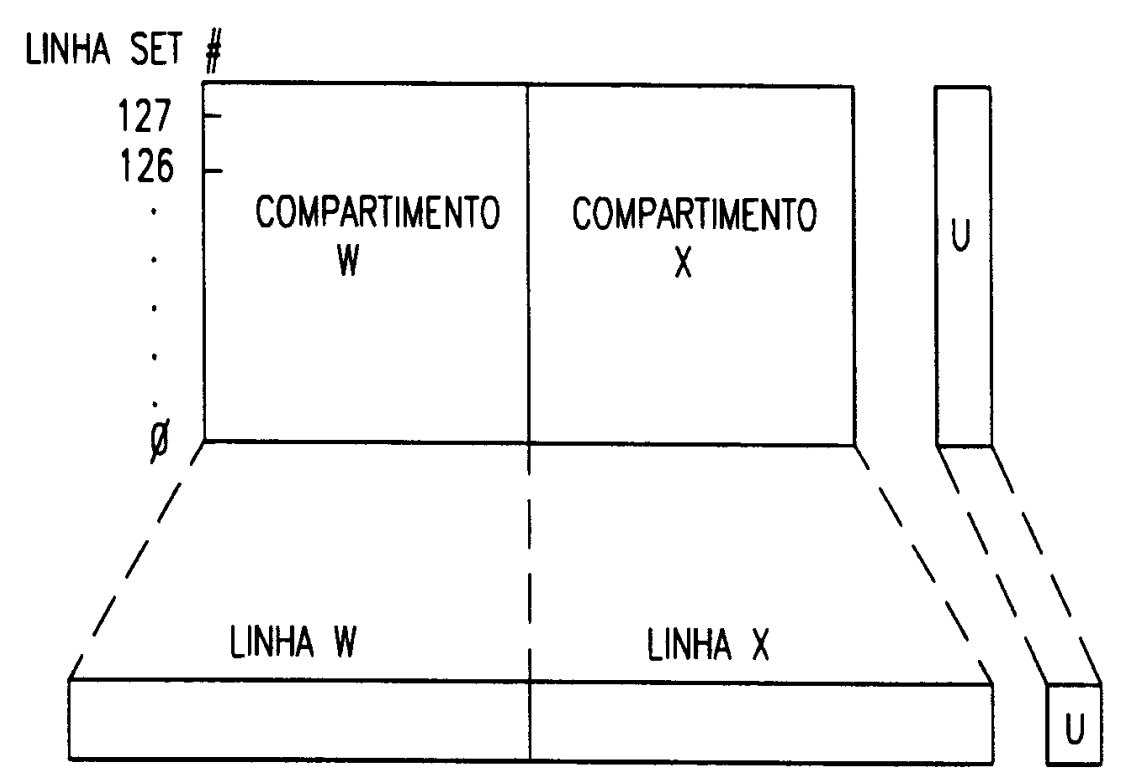

Figura 2.9: Cache do processador Clipper

A arquitetura proposta adota uma cache semelhante a do processador Clipper, por este ser um dos mais eficientes modelos já testados [Smit82]. Porém, ela foi implementada em bloco separado o que permite a conexão/desconexão de diferentes tipos de cache 
com o processador, desde que deseje-se realizar testes relativos a cache, já que a cache implementada é fácil de ser modificada. 


\section{Capítulo 3}

\section{A Arquitetura Proposta}

Neste capítulo será mostrada a arquitetura proposta neste trabalho, que num primeiro estágio ainda se aproxima muito da arquitetura RISC II de Berkeley. Porém ela é do tipo Harvard, já apresentando cache de dados e instrução, separadas. O sistema cache também é diferente do de Berkeley.

\subsection{RISC-LIE}

Para um estudo mais detalhado de arquiteturas RISC, detalharemos aqui toda a rota por onde os dados passam durante a execução de uma instrução. A arquitetura utilizada é aquela proposta neste trabalho, doravante chamada RISC-LIE.

O RISC-LIE inclui um barramento ${ }^{1}$ bus adicional implementando uma arquitetura no estilo Harvard, que se caracteriza por ter diferentes portos de comunicação para dados e instrução. $O$ banco de registradores possui duas portas de leitura e uma de escrita, o que possibilita a leitura simultânea de $R_{s 1}$ e $R_{s 2}$ e a escrita em $R_{d}$ durante um mesimo ciclo de máquina desde que, é claro $R_{d}$ seja diferente de $R_{s 1}$ e $R_{s 2}$.

A arquitetura proposta ainda não possui unidade especial para cálculos em ponto flutuante. Os dados são computados por uma ULA e um deslocador ${ }^{2}$ (Shifter) bidirecional de quantia arbitrária.

\footnotetext{
${ }^{1}$ será referenciado como bus quando for nome de barramento

${ }^{2}$ daqui por diante será sempre referido como Shifter por ser um termo conhecido em computação
} 


\subsubsection{Micro arquitetura}

A figura 3.1 ilustra a micro arquitetura simulada neste trabalho, onde vemos todos os componentes disponíveis na rota dos dados.

- Banco de registradores: 138 registradores de 32 bits, com decodificador de porta dupla e latches $R A, R B, R D$ para manuseio de endereços de uma instrução. $R_{0}$ sempre possui zero (via hardware).

- PSW: 13 bits de estado do processador (processor status word). Inclui CWP, SWP, condições de código CCs, e bits de controle de interrupção (veja apêndice A).

- DST: latch destino, serve também como latch temporária para o pipeline. O resultado de cada operação é mantido nela até que seu valor seja escrito em um registrador apropriado, ou usado durante o próximo ciclo.

- SRC: latch de entrada para o Shifter. DST ou BI são usados como latch de saída do Shifter.

- Shifter: Shifter tipo cross-bar de 32 bits. A quantia a ser deslocada (0-31) é especificada pelo conteúdo da latch quant.SHIFT e decodificada por S.DEC. Um deslocamento da direita para esquerda ocorre quando a informação flui na direção bus $R \rightarrow$ bus $L$, e ao contrário quando o deslocamento é da esquerda para direita.

- AI, BI: latches de entrada da ULA. A ULA não possui latch de saída, ela usa DST ou um dos dois barramentos de saída.

- ULA: unidade lógica-aritmética para inteiros de 32 bits. Realiza adição, subtração, operações bit-a-bit lógicas (and, or, xor), ou passa o conteúdo de BI para saída.

- BAR: registrador de endereçamento de byte, que computa e manuseia os dois bits menos significativos da soma de $A I$ e $B I$. Quando a ULA está computando um endereço efetivo, $B A R$ irá conter parte do endereço para alinhamento de dado dentro de uma palavra.

- NXTPC: registrador do próximo contador de programa (next program counter), que possui o endereço da próxima instrução a ser buscada durante o ciclo corrente. 
- INC: um incrementador que computa $N X T P C+4$.

- PC: contador de programa, possui o endereço da instrução que está sendo executada durante o ciclo corrente.

- LSTPC: último PC (last PC) possui o endereço da última instrução executada, ou que se tentou executar. Quando uma interrupção ocorre, LSTPC conterá o endereço da instrução interrompida durante o primeiro ciclo após a interrupção, pois já no segundo ciclo, $L S T P C$ conterá o endereço da primeira instrução da rotina interrupção.

- IMM: latch que manuseia os 19 bits menos significativos da instrução, caso ela contenha uma constante imediata.

- DIMM: latch combinado com um circuito que extende o sinal ou preenche com zeros. Manuseia dados vindos da cacheD ou operandos imediatos vindos de $I M M$.

- OP: manuseia o código da operação, o bit SCC, e o bit de operando imediato (ver figura 2.2).

- busA, busB: barramentos do banco de registradores.

- busD: barramento usado para alimentar $A I$ e $D S T$

- busR, busL: barramentos do Shifter, busR é também utilizado para alimentar BI, enquanto busL é usado também para introduzir dados vindos de DIMM na rota dos dados.

- busDADO: usado para buscar/enviar dados e endereços à cache de dados.

- busINSTR: usado para endereçar instruções na cache de instruções, e para alimen$\operatorname{tar} R A, R B, R D, I M M$ e $O P$.

- cacheD: cache de dados.

- mmuD: unidade de gerenciamento de memória de dados (interna à cacheD).

- cacheI: cache de instruções. 
- mmuI: unidade de gerenciamento de memória de instruções (interna à cacheI).

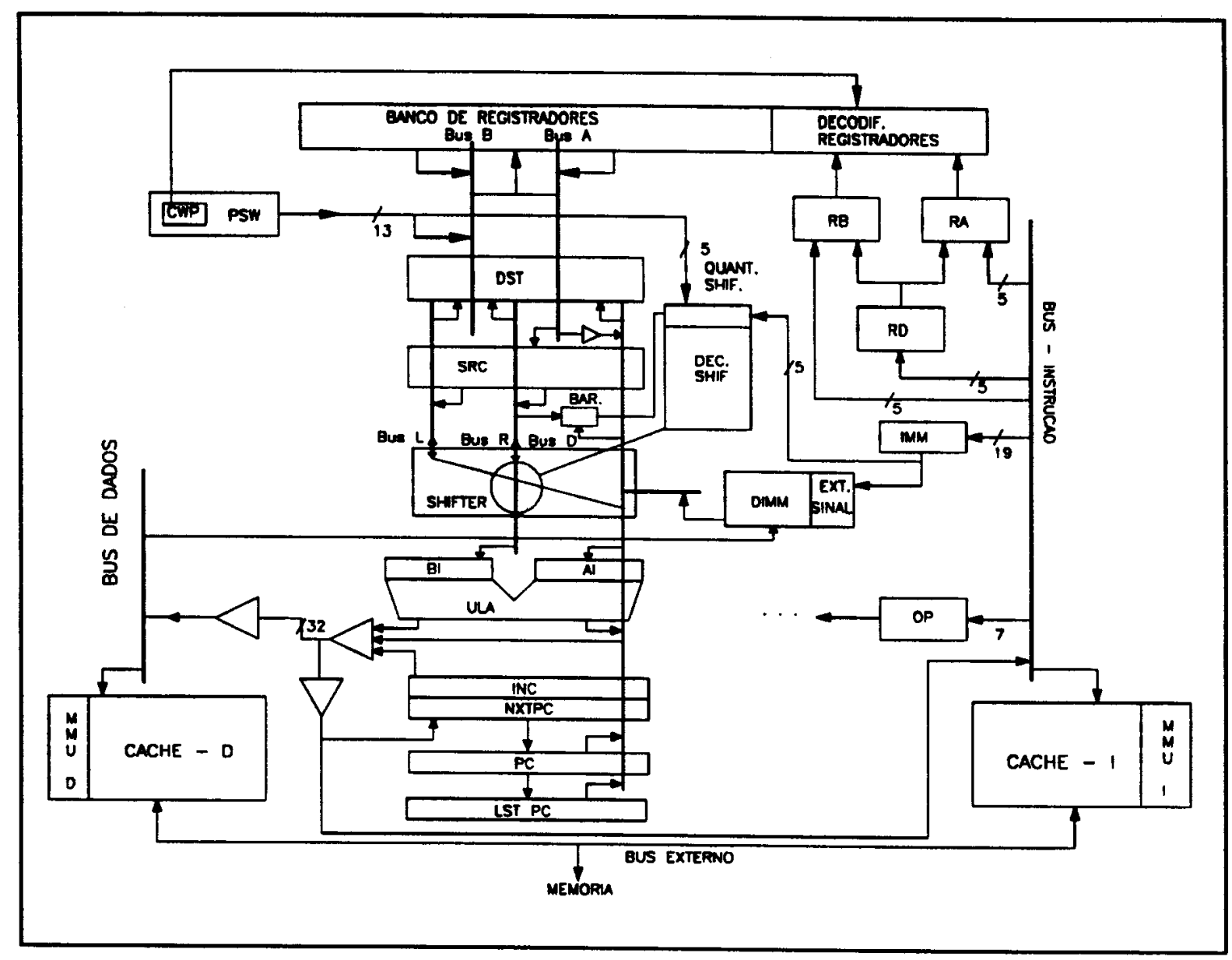

Figura 3.1: Micro Arquitetura RISC-LIE

\subsubsection{Caminhos dos dados na execução de instrução}

Existem poucas atividades que podem estar ocorrendo, durante cada ciclo de máquina:

- Duas fontes apropriadas $S 1$ e $S 2$ são roteadas para a ULA ou Shifter. 
- A saída da ULA ou do Shifter ou o PC é roteado para $D S T$, para que possa ser escrita no seu destino final, durante o próximo ciclo.

- Endereços ou dados são roteados para memória e/ou para os PCs.

A figura 3.2 ilustra como duas fontes apropriadas $S 1$ e $S 2$ (p.e. r1 e r2) são roteadas para as entradas $A I$ e $B I$ da ULA (caminhos utilizados em negrito). $S 1$ pode ser um registrador ou pode ser $\mathrm{PC}$ para endereçamento $\mathrm{PC}$-relativo. $S 2$ pode ser um registrador ou uma constante imediata, ou ainda $P S W$ para a instrução getpsw.

Registradores $R_{s 1}$ e $R_{s 2}$ são lidos através dos barramentos busA e busB. No caso de ocorrer dependência de dados com a instrução prévia, a técnica de adiantamento interno é aplicada (ver cap. 2), e DST coloca seu conteúdo no(s) barramento(s) busA e/ou busB.

A entrada $A I$ da ULA é alimentada via bus $D$, que possui dado vindo de $\mathrm{PC}$ ou busA, dependendo se uma instrução PC-relativo ou normal está sendo executada. A entrada $B I$ da ULA é alimentada via busR que está conectado ao busB através de $S R C$, quando $S 2$ é um registrador ou $P S W$, e neste caso o busR está desconectado do busL. Quando $S 2$ é uma constante imediata, busR é alimentado por DIMM via busL através do Shifter. A latch IMM de 19 bits é conectada a $D I M M$ de forma a preencher os bits mais significativos desta, enquanto que os restantes menos significativos são preenchidos com zeros. Quando a instrução contém uma constante imediata de 13 bits, o circuito extendedor de sinal converte-a numa de 19 bits. Ao entrar no Shifter, esse valor imediato permanece alinhado a esquerda para a instrução ldhi ou é feito um deslocamento de 13 posições à direita, extendendo-se o sinal, para todas as outras instruções.

A figura 3.3 mostra como se roteia dados de forma apropriada para o Shifter. Para instruções deslocamento (shift), a quantia a ser deslocada é $R_{s 1}$, que é lido através do busA e colocado em $S R C$, que então guia busR para um deslocamento da direita para esquerda, ou busL, caso contrário. A quantia a ser deslocada é $S 2$, podendo ser um registrador ou uma constante imediata. Assim SHam é carregado pelos 5 bits menos significativos de $I M M$ ou por busB (neste caso $R_{s 2}$ ).

Um outro caso é quando o dado está vindo ou indo para a memória, necessitando alinhamento. Quando isto ocorrer, a quantia para deslocamento é especificada por $B A R$, e DIMM servirá como entrada do Shifter, onde observamos que, para dados vindos da 


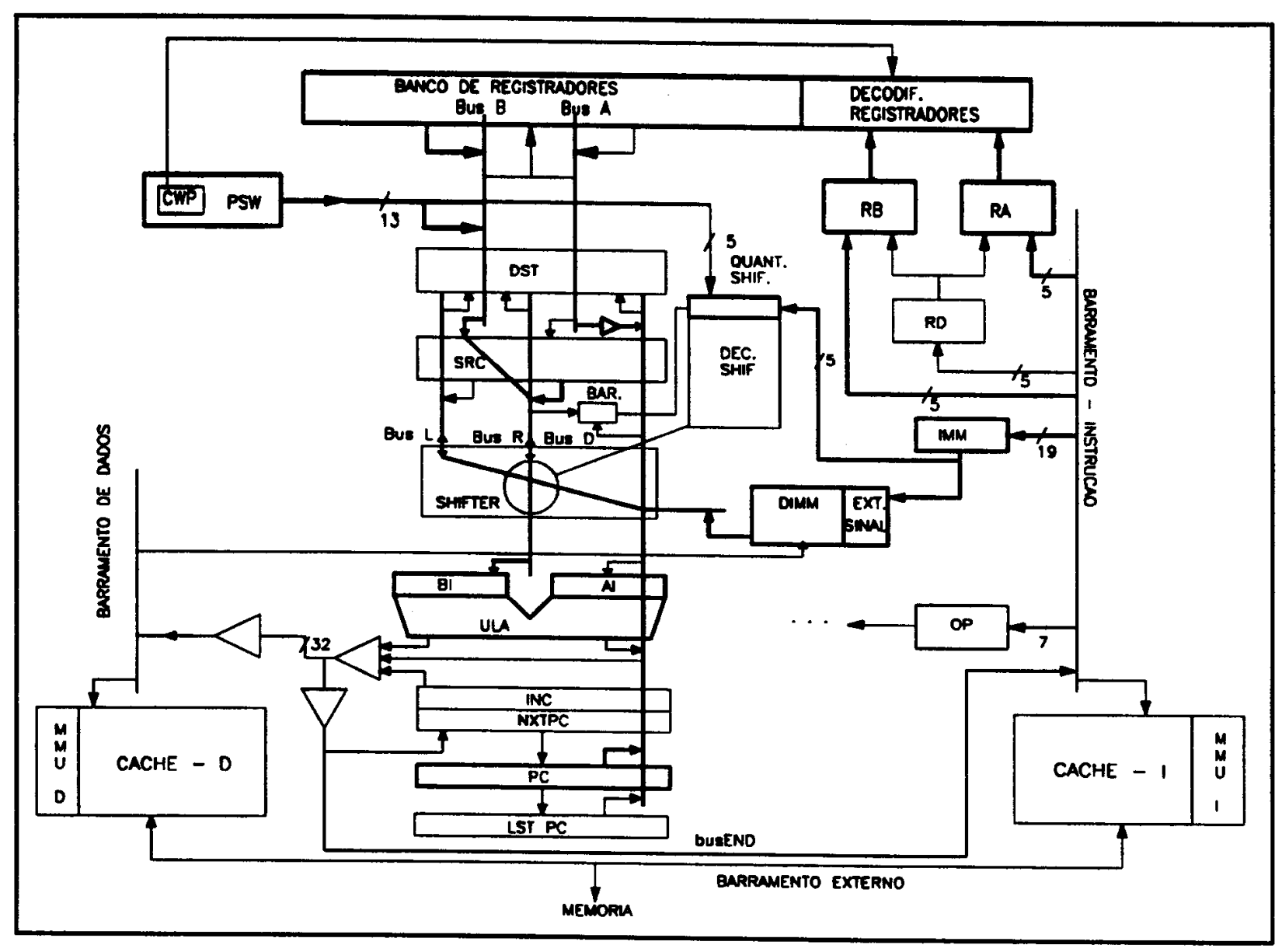

Figura 3.2: Caminhos para a ULA 
memória, necessita-se somente alinhamento da esquerda para direita. Quando uma instrução store necessitar alinhamento, o dado contido em $R_{d}$ é lido através do busB e colocado em $S R C$. Os modos de endereçamento de instruções store foram limitados para que se possa ter uma constante imediata $\mathrm{S} 2$; assim, o busB pode ser utilizado para leitura ao mesmo tempo que bus $A$ está sendo usado para se ler o registrador de índice $R_{s 1}$, enquanto busL e busR são usados para se levar o valor imediato para $B I$.

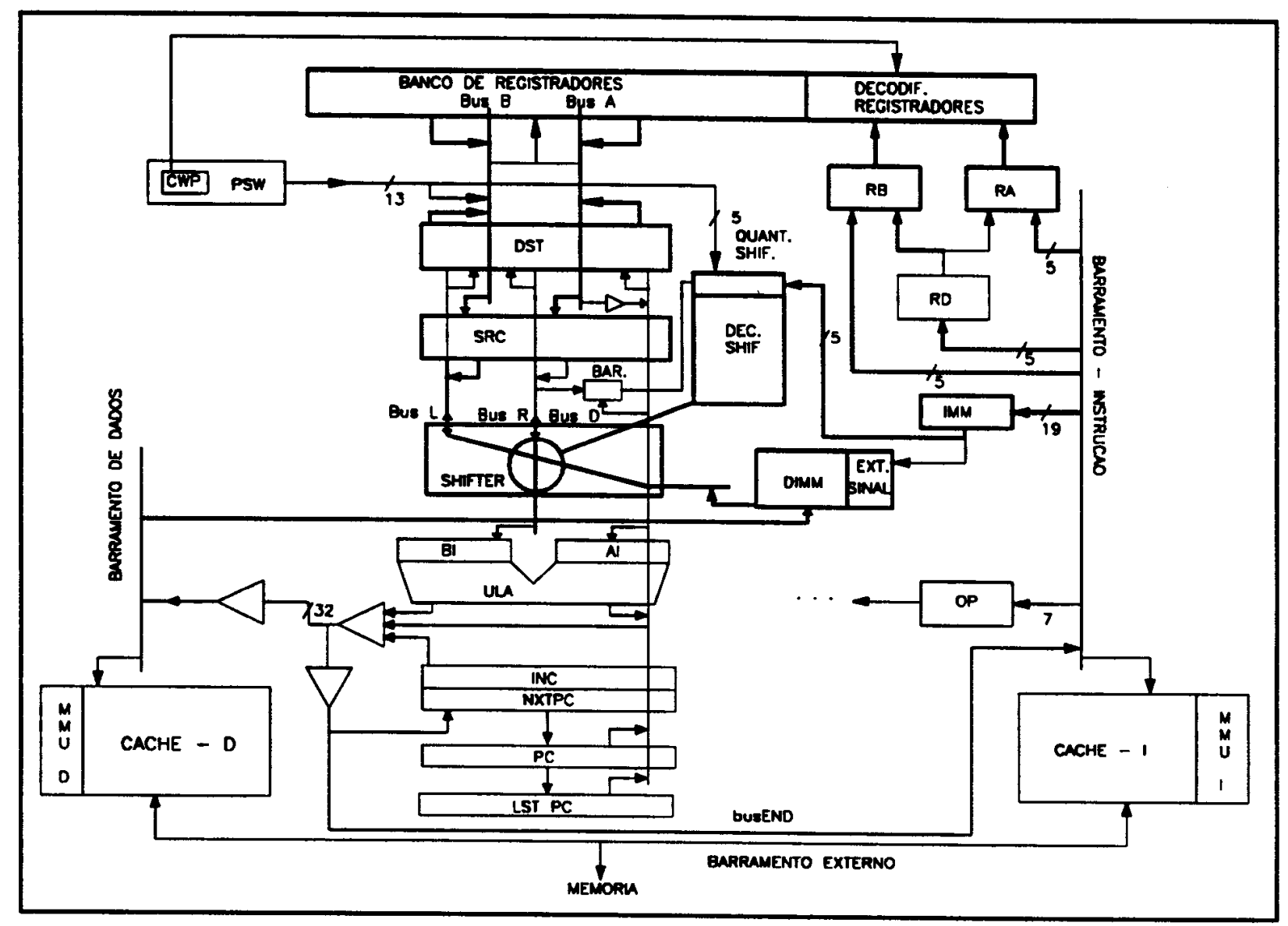

Figura 3.3: Caminhos para o Shifter

A figura 3.4 mostra como a saída da ALU ou do Shifter ou dos PCs são roteadas para $D S T$, e mais tarde escrita no seu destino final, que para a maioria das instruções é $R_{d}$, e 
PSW para a instrução putpsw. Dados a serem escritos nestas locações podem se originar:

- da ULA, para instruções lógicas/aritméticas, putpsw, getpsw e ldhi. As duas últimas instruções usam a ULA no modo onde BI é passado intacto para a saída.

- do Shifter, para instruções shift ou load.

- de PC, no caso de instruções call que deve salvar o endereço corrente em $R_{d}$, para ser usado pela instrução return.

- de $L S T P C$, para instruções calli e getlpc, que são usadas em interrupções para se salvar o endereço da instrução interrompida, e da instrução que estava sendo buscada quando ocorreu a interrupção.

O busD é usado para conduzir dados da saída da ULA, PC ou LSTPC para DST. A saída do Shifter vem de busR ou busL, dependendo da direção de deslocamento. DST manuseia estes resultados até que o último estágio do pipeline escreva-o em $R_{d}$ ou $P S W$ no tempo apropriado, usando bus $A$ ou busB.

A figura 3.5 mostra como dados e endereços são roteados para memória, e como os $P C s$ trabalham. O caminho utilizado para se mandar endereços para cacheI é o barramento busEND. Endereços para busca de instruções são fornecidos pela saída da ULA, no caso de transferência de controle, ou pelo INC-NXTPC em todos os outros casos.

O $N X T P C$ é sempre carregado por busEND, qualquer que seja o endereço de busca de instrução. Os registradores PC e LSTPC seguem o conteúdo de $N X T P C$ com atraso de um e dois estágios de pipeline respectivamente.

Endereços para acesso à dados em memória sempre são fornecidos pela saída da ULA. No caso de instruções store, após o envio do endereço, é enviado o dado vindo via $R_{d}$, DST, busA e busD.

Com isto completamos uma descrição total da arquitetura adotada neste trabalho. O simulador em questão, simula todo o fluxo de dados descrito neste capítulo, além das caches que foram discutidas no capítulo anterior. 


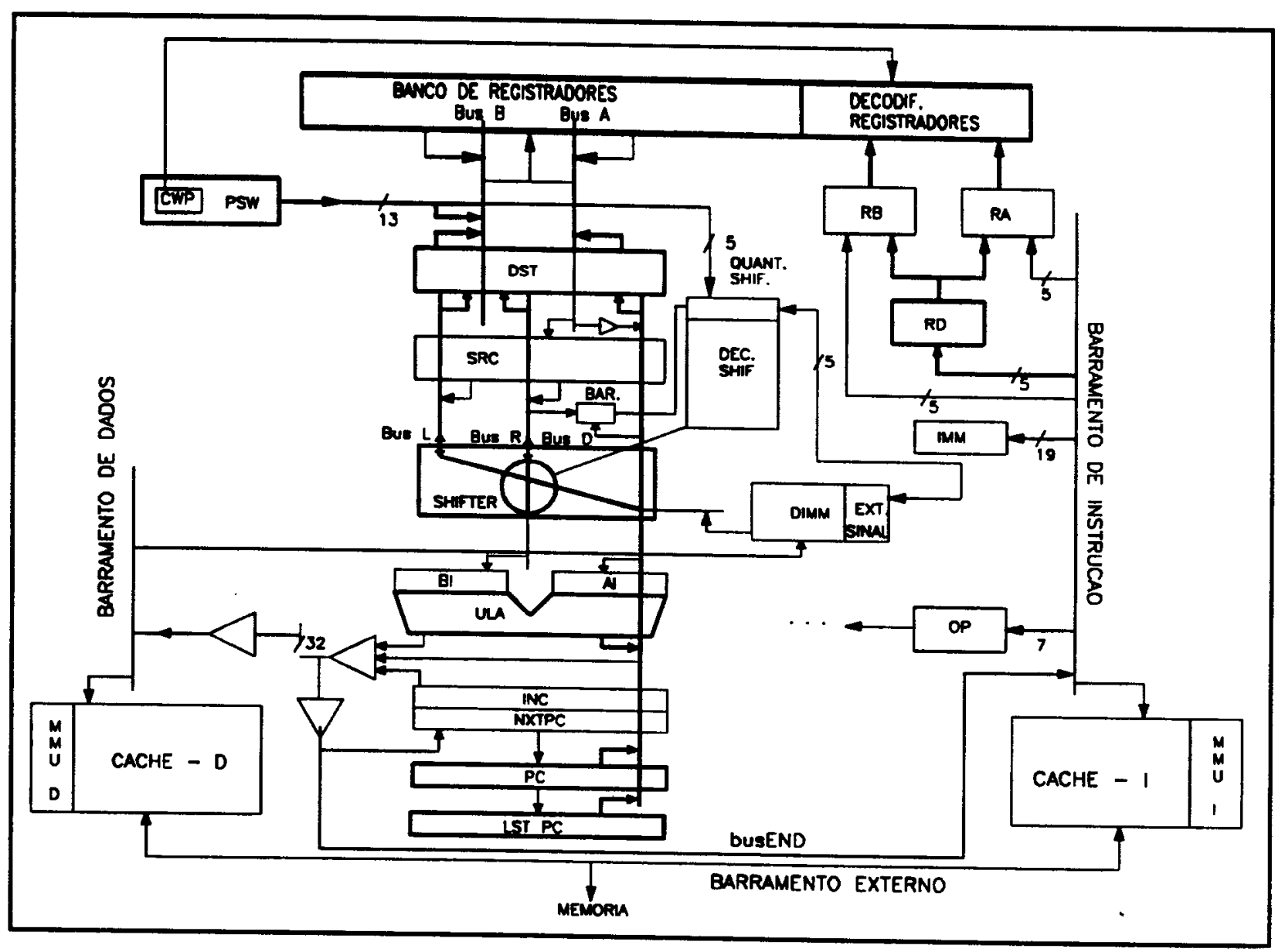

Figura 3.4: Fluxo através de DST 


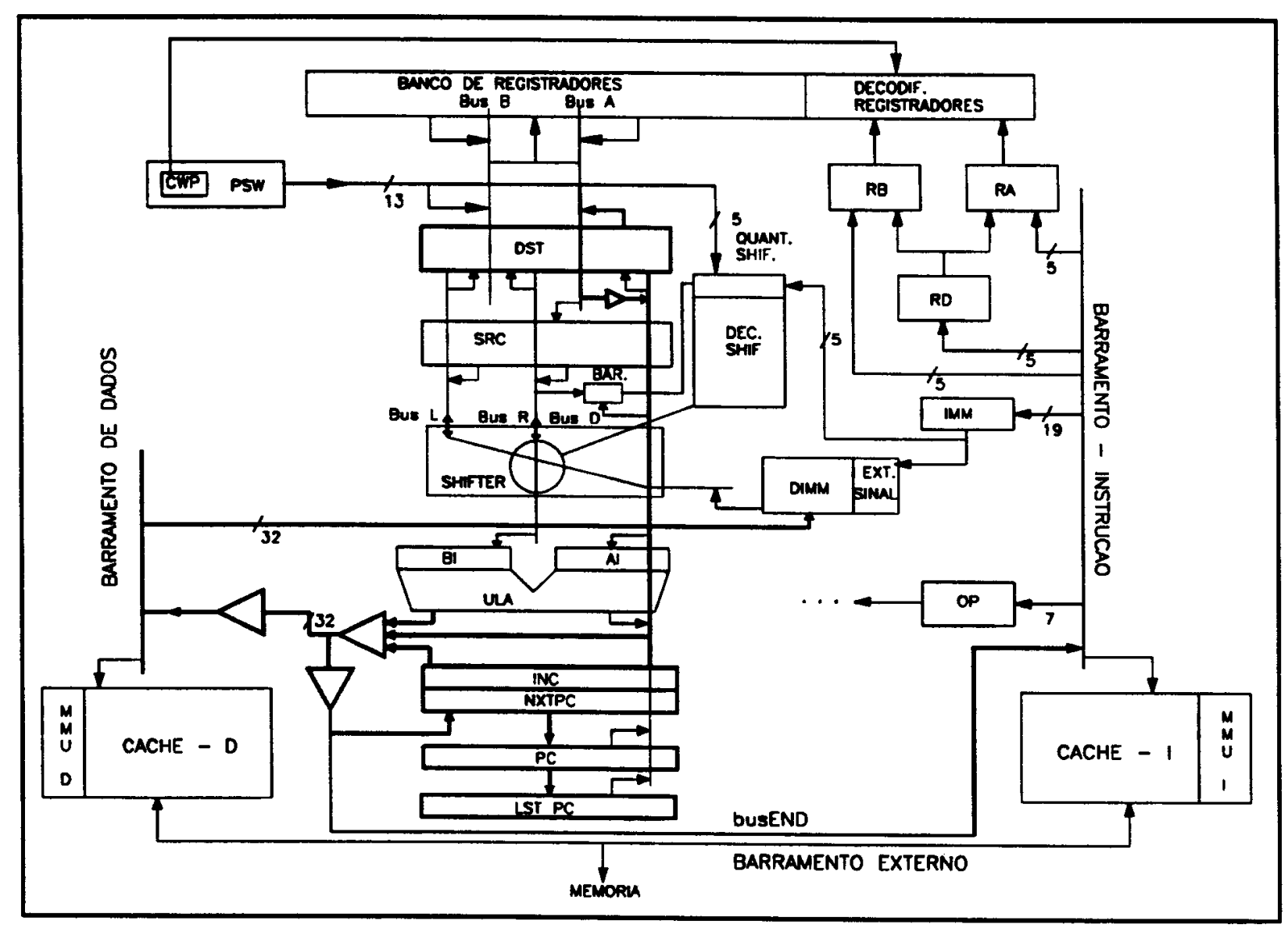

Figura 3.5: Fluxo de dados de/para memória 


\section{Capítulo 4}

\section{O Simulador RISC-LIE}

Este capítulo descreve como funciona o simulador desenvolvido neste trabalho; mostra também como usá-lo.

\subsection{Modelo de simulação}

Técnicas de simulação são utilizadas para se estudar fenômenos que vão desde a dinâmica de vôo de aviōes supersônicos à teoria de processos cognitivos.

O tipo de simulação adotada aqui, e que tem sido até então o mais apropriado para modelamento de sistemas de computação, é a simulação de eventos discretos [Ston75]. $\mathrm{O}$ algorítmo abaixo mostra a estrutura básica de tal simulação:

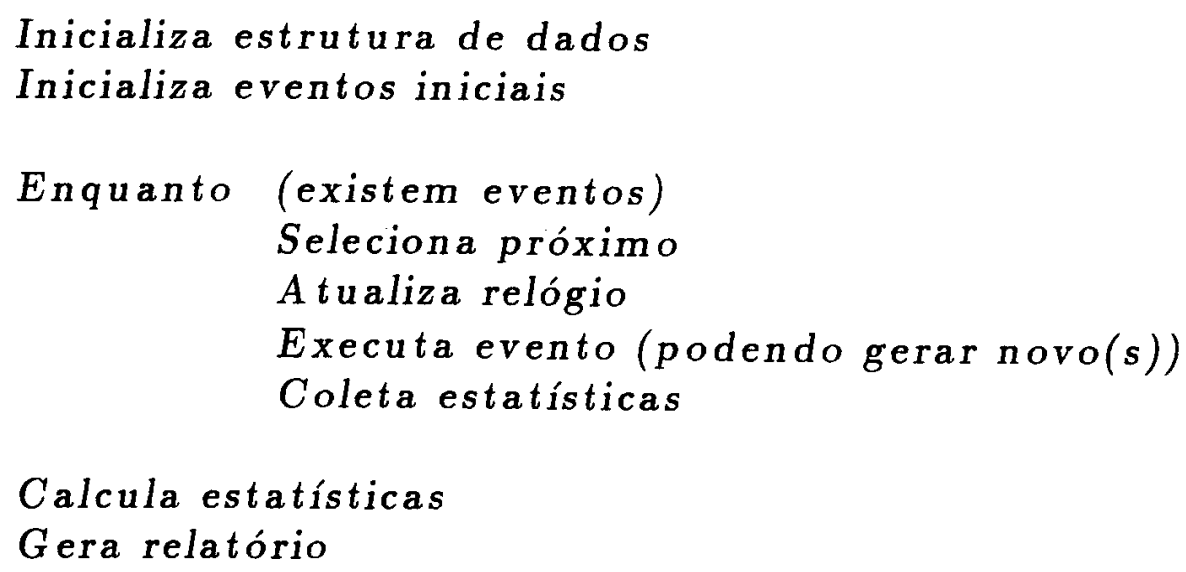

A característica principal é que a simulação é dirigida a eventos; em outras palavras, tempo não é uma variável contínua nem é incrementado em intervalos uniformes no modêlo, sendo incrementado quando da ocorrência do próximo evento. 
A execução de um evento se dará, em nosso caso, pela complitude de todas as tarefas realizadas durante um ciclo de máquina do processador em questão.

Após o processamento de um evento, o relógio do simulador é atualizado para o próximo evento e o processo é repetido.

Para escrever tal simulador, utilizou-se da linguagem $\mathbf{C}$ [KeRi88] pela sua grande portabilidade, e pelos recursos de manipulação de dados a nível de bits.

\subsection{Geração do Modelo}

Para se entender o porquê do modelo gerado, é necessário antes de mais nada conhecer-se o tipo de código que será simulado. Abaixo é mostrado um trecho de um programa no formato de código que "roda" neste simulador (detalhes sobre instruções no apêndice A).

$\begin{array}{ll}\text { add } & r 0, \# 65, r 5 \\ \text { add } & r 0, r 0, r 4 \\ \text { ldxw } & (r 1) 12, r 16 \\ \text { add } & r 16, r 0, r 17 \\ \text { callx } & r 10,(r 0) 2056 \\ \text { or } & r 15, r 0, r 0,\{c\} \\ \text { jmpr } & \text { ne,\#12 } \\ \text { add } & r 7, r 8, r 8 \\ \text { add } & r 0, \# 3, r 17 \\ \text { or } & r 16, r 0, r 0,\{c\} \\ \text { jmpr } & n e, \# 20 \\ \text { add } & r 0, r 10, r 11 \\ \text { add } & r 0, r 0, r 17 \\ \text { jmpr } & \text { alw, } \$ 84 \\ \text { add } & r 0, r 12, r 9 \\ \text { xor } & r 16, \# 1, r 0,\{\mathrm{c}\}\end{array}$


Para suportar tal sequência de código, a função inicializar() faz uma alocação de memória do tamanho da estrutura abaixo, quantas vezes for o número de linhas do programa. A partir daí, a função memorizar(mem) (loader do simulador) "carrega" o programa na região alocada, apontada por mem.

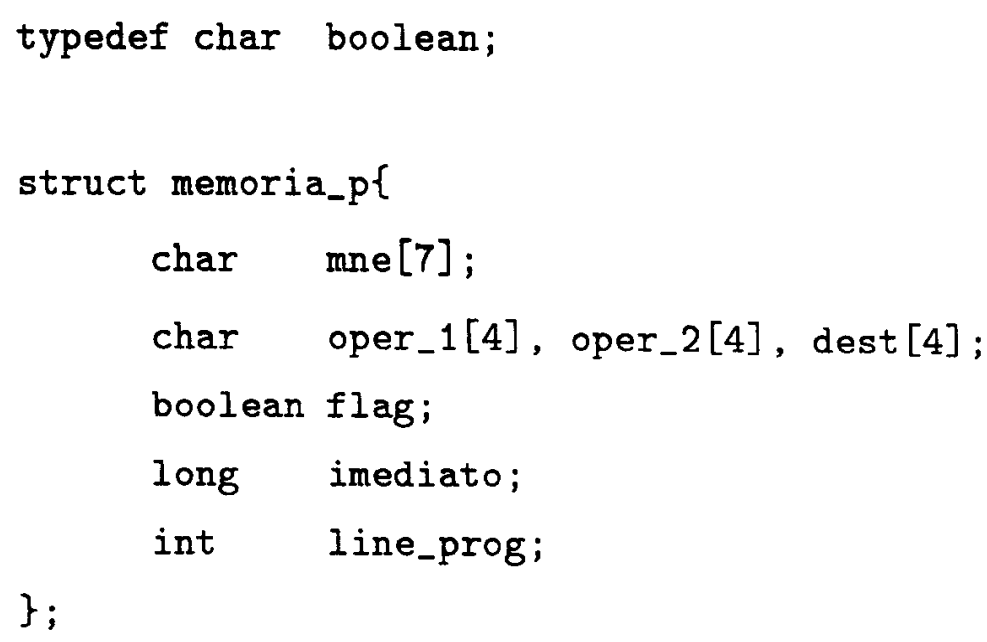

Cada estrutura mostrada acima guarda uma linha de programa, com todas as informações necessárias para execução da simulação. Além do mnemônico e dos três operandos, a variável flag indicará se as condições de código serão afetadas, imediato substituirá oper_2 no caso de operando imediato, e como informação adicional, line_prog possui o número da linha de programa.

Para concluir a geração do modelo, as funções init_data() e initPCs(mem) fazem a inicialização da memória de dados (atualmente $500 \mathrm{~Kb}$ ), das janelas de registradores, do pipeline e dos contadores de programa (PCs).

\subsection{Simulação do Modelo}

Uma vez gerado o sistema, o controle do simulador é passado para a função runner(), que controla todo o pipeline. 


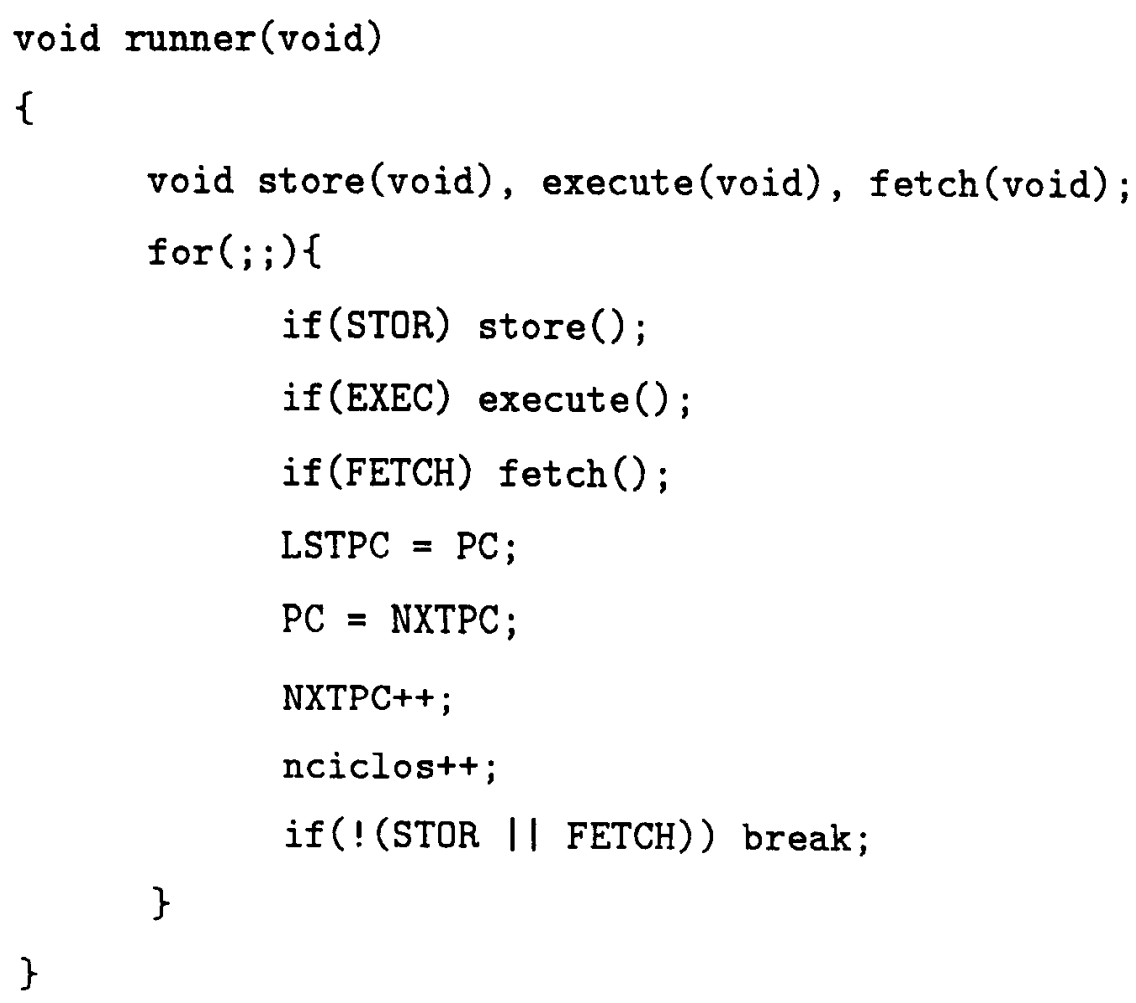

Como mostrado no capítulo anterior, $L S T P C$ e $P C$ seguem o conteúdo de $N X T P C$ com atraso de dois e um ciclos de máquina, respectivamente.

O relógio é atualizado por nciclost+ a toda vez que os três estágios do pipeline terminam suas tarefas, simulando assim os eventos realizados durante um ciclo de máquina. A cada ciclo, cada estágio do pipeline está agindo sobre uma instrução diferente. O controle disto é possível através do uso das flags STOR, EXEC e FETCH que permitem ou não o acesso aos estágios do pipeline.

A função $f e t c h()$ realiza a busca de instrução, decodificação de instrução e operandos. Isto é feito de forma extremamente rápida, comparando-se o mnemônico da instrução com uma tabela de instruções. 


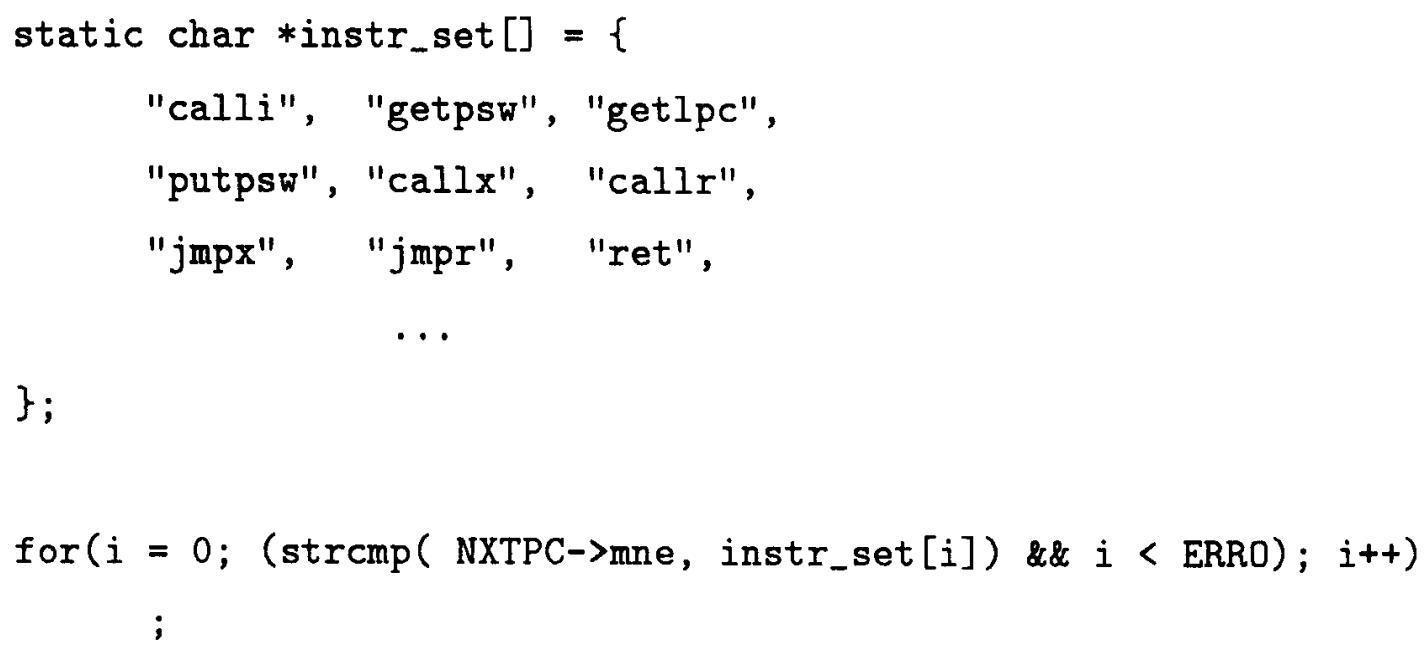

Quando ocorre o match, o valor de $i$ será roteado para a latch apropriada, no caso $O P$. Tanto os operandos como as condições de jump são decodificados da mesma forma. Quando existe operando imediato, sua latch correspondente indicará presença de valor imediato.

Após o término da decodificação, a função execute() fará busca de operandos, testará a dependência de dados para uma possível transmissão interna, e a instrução a ser executada será disparada usando-se o conteúdo da latch $O P$ da seguinte forma:

$$
\text { (*operation }[\text { latch.OP]) (); }
$$

A função correspondente é executada por meio de ponteiros para funções, contidos em um array de ponteiros para funções.

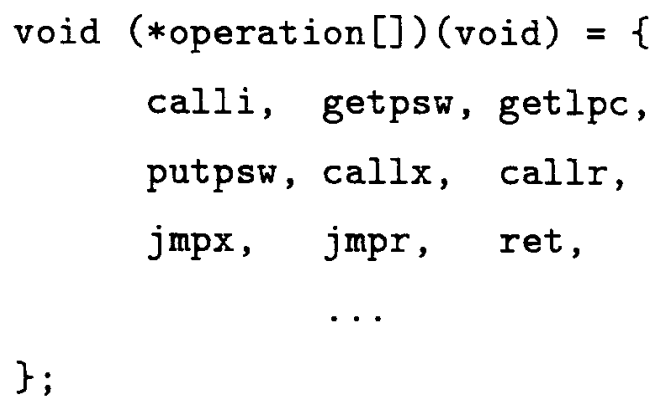

Esta técnica possibilitou uma sequência de código (do programa simulador) bastante compacta e muito rápida, tornando o simulador somente 90 vezes mais lento que o computador utilizado para a simulação. 
No caso de instruções call/return a função transfer_control() controla a troca de janelas de registradores.

Todas as outras tarefas, destinadas ao alinhamento de dados, extensão de sinal, testes de condição de jump, controle de jump atrasado e outras tarefas pertinentes a acessos à memória, são feitas por funções ativadas de dentro do estágio execute do pipeline.

O estágio store do pipeline roteará o conteúdo da latch DST para seu destino final.

A coleta de estatísticas é feita a cada instrução executada.

\subsection{Comandos do Simulador}

Para executar um programa no simulador basta digitar (para UNIX e VMS):

$\$$ risc [nomearq] 〈RET>

O simulador carregará o programa escrito em linguagem de máquina RISC.LIE ${ }^{1}$ na memória, e responderá com:

RISC>

O simulador estará automaticamente em modo trace, sendo que a cada vez que se digita RET, uma instrução será executada, e será impresso na tela o estado de todos os registradores da janela corrente, as condições de código, $S W P$ e CWP. É impresso também a instrução apontada por $L S T P C$ acompanhada de seu endereço de memória.

O comando $\ln n$ onde $n n$ é um número inteiro, listará $n n$ linhas do programa a partir daquela apontada por LSTPC.

g $n n$ executará $n n$ instruções e o estado dos registradores somente será mostrado após a execução da instrução $n n$.

d $n n$ fará $d u m p$ da página $n n$ da memória de dados.

O comando e suspende a execução, e devolve o controle para o sistema operacional.

\footnotetext{
${ }^{1}$ ver apêndice $A$
} 


\subsection{Estatísticas apontadas pelo simulador}

Devido a grande modularidade do simulador em questão, é muito fácil coletar-se uma gama muito variada de dados durante a simulação de um programa.

$\mathrm{Na}$ atual versão deste simulador RISC, pode-se obter, por exemplo, o número de vezes que cada instrução foi executada, podendo com isto estudar-se quais são as instruções mais requeridas pelo compilador ${ }^{2}$. Além disto, o simulador acusa o número total de instruções executadas, o número de ciclos de máquina gastos por todas estas instruções e o número de instruções executadas por ciclo.

Quando as caches estão conectadas, no final da execução de um determinado programa, é acusado o número de hits, miss e o hit-ratio das caches. Pode-se alterar de forma extremamente simples o tamanho das caches, e seu grau de set-associativity.

Uma instrução especial chamada time (tabela A.1), e que não fará parte da arquitetura final, foi adicionada ao conjunto de instruções. Esta instrução possibilita a leitura do "relógio" do sistema, e assim conseguimos então medir tempos de execução de determinados trechos de programa. Este tipo de medida se faz necessária no cálculo de desempenho da arquitetura.

Pode-se mudar a velocidade do processador, alterando-se o valor da variável frequência (em MHz).

Um tipo de estatística que poderia ser facilmente levantada, seria a medição da profundidade de aninhamento de procedimentos, para com isso determinar-se qual o tamanho e número de janelas de registradores seria mais adequado nesta arquitetura. Porém isso não foi feito pois tem-se já muitos resultados com respeito a esta questão, e adotamos o mais recomendado pelas estatísticas coletadas por Tamir em [TaSe83].

Por simular toda a rota dos dados, pode-se acrescentar contadores onde quer que se deseje medir "tempos" na hora de se projetar o circuito lógico da arquitetura.

\footnotetext{
${ }^{2}$ Um compilador Pascal para esta arquitetura está sendo desenvolvido num trabalho paralelo a este
} 
Todas as variáveis que manipulam dados na rota dos dados na arquitetura são do tipo unsigned (sem sinal em linguagem C), e assim é possível tratar dados com ou sem sinal.

A decisão de se simular toda a rota dos dados na arquitetura, se deve a uma comunicação privada com Yuval Tamir [Tami89], que há alguns anos atrás construiu um simulador semelhante durante o projeto RISC na Universidade de Berkeley. 


\section{Capítulo 5}

\section{Desempenho}

Nos últimos anos, tem havido um grande interesse com respeito á interação entre as linguagens de programação e a arquitetura de computadores [Weik84].

Como uma máquina de linguagem de alto nível, a arquitetura deve executar eficientemente aquelas características da linguagem de programação, que são mais utilizadas pelos programas atuais.

Esta habilidade é frequentemente medida por programas conhecidos como benchmarks.

A palavra benchmark se refere a um único programa [Weic84], que reflete a frequência dos comandos do programa fonte (linguagem de alto nível) em programas reais, e a frequência destes comandos na forma compilada, em sua correspondente linguagem de máquina. Portanto é inevitável que tal benchmark meça não só a arquitetura da máquina, mas também a habilidade do compilador gerar uma sequência de código eficiente.

\subsection{Dhrystone Benchmark}

A partir de vários artigos, que diziam respeito ao aspecto desempenho de diferentes computadores, Reinhold P. Weicker, construiu um benchmark baseando-se nas estatísticas disponíveis nestes artigos, chamado Dhrystone, uma analogia ao benchmark Whetstone [Weic84].

O programa Dhrystone [Weic84], é de fácil implementação; entretanto possui certas características, como influências da cache por exemplo, que devem ser levadas em conta quando comparamos diferentes arquiteturas, ou diferentes compiladores.

A grande vantagem de se usar este benchmark, é que ele já foi aplicado a mais de 
300 máquinas diferentes, e os resultados têm sido amplamente divulgados [Inte89]. Este programa foi especificamente construído para se medir o desempenho da UCP e do compilador, e não possui outro objetivo além deste. Foi originalmente introduzido em 1984, numa versão em $\mathrm{ADA}$, e mais tarde em $\mathrm{C}$.

Este benchmark é balanceado com respeito aos diferentes tipos de declarações, de linguagens de alto nível, tipos de dados, e acessos à operandos. A tabela 5.1 mostra a porcentagem de distribuição de declarações de alto nível (C):

Tabela 5.1: Declarações no Dhrystone

\begin{tabular}{|c|c|}
\hline Tipo de Declaração & Porcentagem \\
\hline atribuições & $51.0 \%$ \\
declarações de controle & $32.4 \%$ \\
procedimentos, calls & $16.7 \%$ \\
\hline
\end{tabular}

Apesar da maioria dos benchmarks realizarem medidas de desempenho em segundos, Dhrystone mede Dhrystones por segundo, sendo que números maiores indicam desempenho melhor.

Qualquer que seja o benchmark que se use, sempre existirá a tendência de se olhar somente para o resultado final. Existem muitas áreas onde detalhes (influência da linguagem, influência do compilador, método de medida, influência da cache) devem ser verificados cuidadosamente, quando estamos comparando diferentes processadores ou sistemas [LeCl82].

Existem limitações inerentes a um número único (como o resultado de um benchmark) se ele é usado como "único" critério para avaliação de arquiteturas de processadores ou compiladores. Entretanto, se usado de forma cuidadosa, um benchmark como o Dhrystone pode ser de muito valor na área de interfaceamento entre a linguagem de programação e a arquitetura do computador, ponto vital do desenvolvimento da arquitetura RISC.

A tabela 5.2 mostra alguns dos resultados divulgados em [Inte89]. 
Tabela 5.2: Resultados do Dhrystone

\begin{tabular}{|clcl|}
\hline Dhrystones/seg & Máquina & Clk,MHZ & UCP \\
\hline 74074 & Amdahl 5990-700 & & \\
41500 & Cray X-MP/4-16 & & \\
40210 & Cypress chip set & 33 & SPARC \\
33247 & Platform-88 & 20 & Motorola 88100 \\
22590 & MIPS M/1000 & 16 & MIPS R2000 \\
18048 & Sun4/260 & 16 & SPARC \\
10000 & Delta Series VME & 25 & Motorola 68030 \\
8991 & DEC 8800 & & \\
7146 & Sun3/260 & 25 & Motorola 68020 \\
7025 & Prime EXL 316 & 25 & Intel 386DX \\
5714 & Apollo DN4000 & 25 & Motorola 68020 \\
5400 & Compaq 386s & 25 & Intel 386SX \\
3413 & AEON 330/AT & 15 & National 32332 \\
2469 & Apple Mac II & 16 & Motorola 68020 \\
1517 & DEC VAX 11/780 & & \\
\hline
\end{tabular}

\subsection{Resultados obtidos no IFQSC}

A partir da versão escrita em linguagem C, do benchmark Dhrystone, e seguindo-se recomendações de Weicker [Weic84], rodamos o benchmark em alguns computadores disponíveis no Instituto de Física e Química de São Carlos. Os resultados são mostrados na tabela 5.3. $\mathrm{Na}$ mesma tabela é mostrado o resultado obtido no simulador RISC. Para efeito de comparação, deve-se lembrar que no teste realizado no simulador, o programa Dhrystone foi escrito em linguagem de máquina RISC.LIE, ou seja, foi compilado a mão a partir da listagem fonte (em linguagem C) do Dhrystone. 
Tabela 5.3: Resultados do Dhrystone no IFQSC

\begin{tabular}{|clcl|}
\hline Dhrystones/seg & Máquina & Clk,MHZ & UCP \\
\hline 1230 & DEC VAX 11/780 & & \\
1660 & AT 286 & & Intel 286 \\
2740 & Apple MacIntosh II & 16 & 68020 \\
3300 & AT 386SX & 10 & Intel 386 SX \\
6250 & Interpro 32C & 10 & Clipper \\
7650 & Interpro 220 & 25 & SPARC \\
12500 & Sun SPARCstation 1+ GX & 25 & MIPS R2000 \\
12500 & CDC Silicon Graphics & & \\
12500 & DEC VAX 6420 & $\mathbf{2 5}$ & RISC.LIE \\
$\mathbf{3 4 6 2 5}$ & Simulador RISC.LIE & & \\
\hline
\end{tabular}

Na tabela 5.3, ao se analizar o elevado resultado obtido pelo simulador RISC, deve-se levar em conta alguns fatores:

- ainda não se possui um compilador para esta arquitetura, e o programa Dhrystone foi compilado a "mão" a partir de uma versão em linguagem $\mathrm{C}$ deste benchmark.

- por ter sido compilado a mão, o código resultante foi de certa forma otimizado.

- o resultado do Dhrystone é muito influenciado pela cache. Nesta simulação de processo único, o programa todo estava na cache.

- não existe nenhum tipo de interrupção que esteja atrasando o processo, e consequentemente, o tempo de computação do teste é o mínimo possível.

Neste teste realizado com o Dhrystone, notou-se que as caches apesentaram um hitratio de $100 \%$, o que significa que todo o programa estava na cache, e portanto não houve queda no desempenho por influência da cache ${ }^{1}$.

Uma avaliação concreta da arquitetura simulada será feita quando o seu compilador Pascal estiver pronto, quando será então possível simular-se situações onde vários processos estejam disputando a UCP, o que nos dará estatísticas um pouco mais reais.

\footnotetext{
${ }^{1}$ Em [Weic84], Weicker diz que grande parte do resultado realizado com o Dhrystone se deve ao
desempenho das caches
} 
Um outro ponto que contribuirá para a queda do desempenho será a ocorrência de interrupções, item que será possível de simular assim que o compilador Pascal esteja disponível. Simulando-se multiprocessamento dentro do simulador RISC.LIE, um dos processos poderá ser um disparador de interrupções, em tempos aleatórios.

O resultado para o Dhrystone no simulador foi obtido da seguinte forma:

Dhrystones por segundo $=$ número de execuções $\div$ tempo de execução

O número de execuções (50000) foi colocado em um registrador que era decrementado a cada execução do loop principal do Dhrystone [Weic84]. Através da instrução time, executada duas vezes, conseguiu-se medir o número de ciclos gastos na execuçao do programa. Dividindo-se o número de ciclos pelo clock básico da UCP, obteve-se o tempo de execução, e daí o resultado em Dhrystones por segundo.

Abaixo mostramos alguns números obtidos em alguns testes de acesso randômico às caches, e se compararmos com os números mostrados em [Clip87] e [Smit82], veremos que as caches simuladas se comportam de forma idêntica àquelas mostradas em [Smit82] e implementada em [Clip87].

- teste1

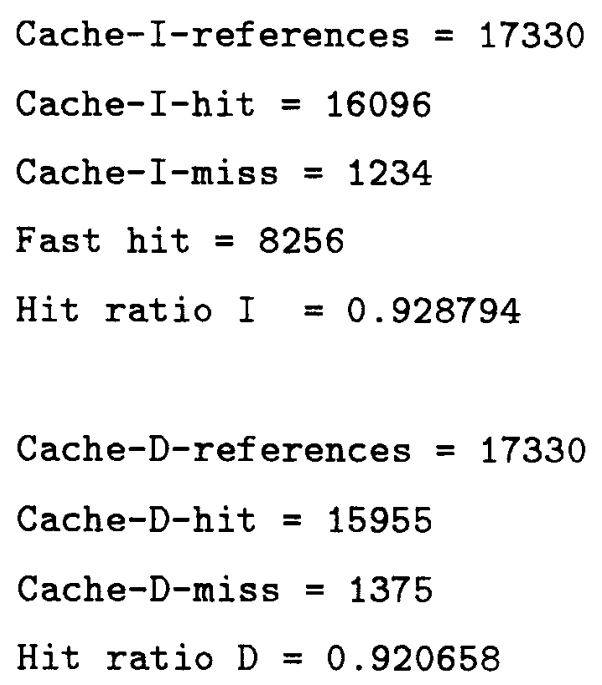


- teste2

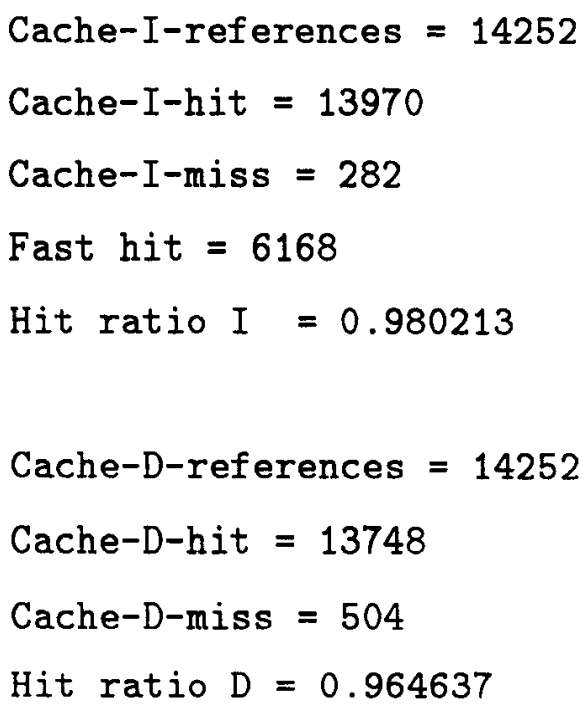

Onde: Fast hit, é o número de hits no buffer de prefetch $(4$ bytes) e hitratio $=$ hit/references.

Levando-se em conta os pontos discutidos, e se pensarmos num fator muito pessimista, digamos uma queda de $50 \%$ no desempenho para um caso real, ou melhor, $50 \%$ deste desempenho no caso de uma implementação desta arquitetura, ainda assim teremos um processador tão rápido quanto os mais rápidos disponíveis no mercado.

Quanto a implementação desta arquitetura, toda ela caberá numa única pastilha, UCP e caches, e ainda sobrará muito espaço para implementação de outros elementos de arquitetura, como por exemplo uma unidade para cálculos em ponto flutuante. 


\section{Conclusões e Futuros Trabalhos}

RISC representa um novo estilo de arquitetura, que possibilita aos projetistas não só, construir pastilhas em tempo menor do que o necessário para construir pastilhas CISC, mas também obter-se um desempenho maior do que CISC.

Máquinas tradicionais suportam linguagens de alto nível através de instruções de máquina muito próximas das de alto nível. RISC suporta linguagens de alto nível com instruções que possam ser usadas eficientemente pelo compilador da linguagem de alto nível.

Com este trabalho, foi possível notar-se que com um conjunto de instruções reduzido, porém bem escolhido, combinado com o restante das características da arquitetura (esquema de janelas, jump atrasado, caches, etc.), pôde-se conseguir um alto desempenho da arquitetura, devido também a redução do tempo de execução das instruções de acesso à memória (estilo Harvard).

Apesar de certas construções de alto nível terem sido trabalhosas de serem implementadas, todas as construções do Dhrystone foram implementadas, o que valida o conjunto de instruções.

Por não possuir uma unidade de cálculos para ponto flutuante, não foi feito nenhum tipo de teste de desempenho para cálculos deste tipo, pois sabe-se que arquitetura RISC possui um desempenho medíocre para estes cálculos sem uma unidade para cálculos em ponto flutuante $[\mathrm{PaSe} 82]$. Uma nova versão desta arquitetura deverá possuir unidade para ponto flutuante.

O simulador desenvolvido neste trabalho mostrou-se ser de grande funcionalidade, e pode-se agora utilizá-lo para estudo e projeto de arquiteturas RISC, nos níveis de definição, medidas de desempenho, medidas de temporização do circuito correspondente, e desempenho de compiladores frente a códigos compilados a "mão". O simulador também se 
presta a outras linhas de pesquisa em arquitetura, como o desenvolvimento de caches, unidades de ponto flutuante, gerenciadores de memória, e todos os demais elementos de arquitetura, pois são de fácil conexão ao simulador. 


\section{Apêndice A}

\section{Características Arquiteturais}

Neste apêndice, detalharemos o conjunto de instruções do RISC.LIE, sua sequência de execução e condições de código.

\section{A.1 Sequência de execução}

A sequência de execução de instruções no RISC.LIE segue a forma usual de von Neumann, exceto pelo esquema de pipeline de instrução, o que resulta no esquema de delayed jump, e pelo esquema de caches de dados e instruções separadas, implementado através de barramento duplo, permitindo-se assim dois acessos à memória num mesmo ciclo ( $§ 2.7)$.

\section{A.2 Conjunto de instruções}

O conjunto de instruções da arquitetura simulada, segue basicamente o mesmo conjunto do RISC II [Kate84], com exceção das instruções de acesso à memória PC-relativas, já que a mudança para o estilo Harvard não permite este tipo de instrução.

A tabela A.1 mostra o conjunto de instruções, separado em quatro grupos:

- instruções lógicas/aritméticas

- instruções de acesso à memória

- instruções de transferência de controle

- e miscelânia de instruções 


\section{A.2.1 Instruções OP registrador-registrador}

Este grupo de instruções (primeiro da tabela A.1), inclue shifts, instruções lógicas e aritméticas inteiras. Todas elas possuem o formato imediato curto ( $\$ 2.5)$, e operam com o registrador rs1 da janela corrente, e com S2. O operando $\mathrm{S} 2$ pode ser um registrador rs2 ou uma constante imediata imm13 de 13 bits com sinal, contida na instrução.

Os registradores são sempre interpretados como quantidades de 32 bits e imm13 é expandida para 32 bits, extendendo-se o sinal. O resultado é escrito em Rd da janela corrente, e a instrução pode opcionalmente habilitar as condições de código, bastando para isso adicionar-se o termo $\{c\}$ (p.e. add rs1,rs2,r10, \{c\}) àquela instrução que se deseja que as CCs sejam afetadas. Este procedimento fará com que o bit-24 da instrução passe para ON. Deve-se lembrar que o registrador r0 sempre possui o valor 0; no entanto, pode-se escrever neste registrador apesar de seu conteúdo não se alterar, porém as flags de condição de código serão alteradas, caso a instrução possua como último termo o indicador $\{c\}$.

A figura A.1 mostra mais detalhes sobre estas instruções. 
Tabela A.1: Conjunto de instruções RISC.LIE

\begin{tabular}{|c|c|c|c|}
\hline instrução & operandos & comentário & nome \\
\hline add & $\mathrm{Rs}, \mathrm{S} 2, \mathrm{Rd}$ & $\overline{\mathrm{Rd}} \leftarrow \mathrm{Rs}+\mathrm{S} 2$ & adição inteira \\
\hline addc & $\mathrm{Rs}, \mathrm{S} 2, \mathrm{Rd}$ & $\mathrm{Rd} \leftarrow \mathrm{Rs}+\mathrm{S} 2+$ carry & adição com carry \\
\hline sub & $\mathrm{Rs}, \mathrm{S} 2, \mathrm{Rd}$ & $\mathrm{Rd} \leftarrow \mathrm{Rs}-\mathrm{S} 2$ & subtração inteira \\
\hline subc & $\mathrm{Rs}, \mathrm{S} 2, \mathrm{Rd}$ & $\mathrm{Rd} \leftarrow \mathrm{Rs}-\mathrm{S} 2$ - carry & subtração com carry \\
\hline subi & $\mathrm{Rs}, \mathrm{S} 2, \mathrm{Rd}$ & $\mathrm{Rd} \leftarrow \mathrm{S} 2-\mathrm{Rs}$ & subtração inteira \\
\hline subci & $\mathrm{Rs}, \mathrm{S} 2, \mathrm{Rd}$ & $\mathrm{Rd} \leftarrow \mathrm{S} 2$ - Rs - carry & subtração com carry \\
\hline and & $\mathrm{Rs}, \mathrm{S} 2, \mathrm{Rd}$ & $\mathrm{Rd} \leftarrow \mathrm{Rs} \& \mathrm{~S} 2$ & "E" lógico \\
\hline or & $\mathrm{Rs}, \mathrm{S} 2, \mathrm{Rd}$ & $\mathrm{Rd} \leftarrow \mathrm{Rs} \mid \mathrm{S} 2$ & "OU" lógico \\
\hline xor & $\mathrm{Rs}, \mathrm{S} 2, \mathrm{Rd}$ & $\mathrm{Rd} \leftarrow \mathrm{Rs}$ xor $\mathrm{S} 2$ & "OU exclusivo" lóg. \\
\hline sll & $\mathrm{Rs}, \mathrm{S} 2, \mathrm{Rd}$ & $\mathrm{Rd} \leftarrow$ Rs shift $\mathrm{S} 2$ & desloc. à esq. \\
\hline srl & $\mathrm{Rs}, \mathrm{S} 2, \mathrm{Rd}$ & $\mathrm{Rd} \leftarrow$ Rs shift $\mathrm{S} 2$ & desloc. lógico à dir. \\
\hline sra & $\mathrm{Rs}, \mathrm{S} 2, \mathrm{Rd}$ & $\mathrm{Rd} \leftarrow$ Rs shift $\mathrm{S} 2$ & desloc. aritm. à dir. \\
\hline ldxw & $(\mathrm{Rx}) \mathrm{S} 2, \mathrm{Rd}$ & $\mathrm{Rd} \leftarrow \mathrm{M}[\mathrm{Rx}+\mathrm{S} 2]$ & carr. palavra \\
\hline ldxhu & $(\mathrm{Rx}) \mathrm{S} 2, \mathrm{Rd}$ & $\mathrm{Rd} \leftarrow \mathrm{M}[\mathrm{Rx}+\mathrm{S} 2]$ & carr. meiap. sem sinal \\
\hline Idxhs & $(\mathrm{Rx}) \mathrm{S} 2, \mathrm{Rd}$ & $\mathrm{Rd} \leftarrow \mathrm{M}[\mathrm{Rx}+\mathrm{S} 2]$ & carr. meiap. com sinal \\
\hline Idxbu & $(\mathrm{Rx}) \mathrm{S} 2, \mathrm{Rd}$ & $\mathrm{Rd} \leftarrow \mathrm{M}[\mathrm{Rx}+\mathrm{S} 2]$ & carr. byte sem sinal \\
\hline ldxbs & $(\mathrm{Rx}) \mathrm{S} 2, \mathrm{Rd}$ & $\mathrm{Rd} \leftarrow \mathrm{M}[\mathrm{Rx}+\mathrm{S} 2]$ & carr. byte com sinal \\
\hline stxw & $\mathrm{Rm},(\mathrm{Rx}) \mathrm{S} 2$ & $\mathrm{M}[\mathrm{Rx}+\mathrm{S} 2] \leftarrow \mathrm{Rm}$ & armaz. palavra \\
\hline stxh & $\mathrm{Rm},(\mathrm{Rx}) \mathrm{S} 2$ & $\mathrm{M}[\mathrm{Rx}+\mathrm{S} 2] \leftarrow \mathrm{Rm}$ & armaz. meiap. \\
\hline stxb & $\mathrm{Rm},(\mathrm{Rx}) \mathrm{S} 2$ & $\mathrm{M}[\mathrm{Rx}+\mathrm{S} 2] \leftarrow \mathrm{Rm}$ & armaz. byte \\
\hline jmpx & $\mathrm{COND},(\mathrm{Rx}) \mathrm{S} 2$ & $\mathrm{pc} \leftarrow \mathrm{Rx}+\mathrm{S} 2$ & desvio condicional \\
\hline jmpr & COND,Y & $\mathrm{pc} \leftarrow \mathrm{pc}+\mathrm{Y}$ & desvio relativo \\
\hline callx & $\mathrm{Rd},(\mathrm{Rx}) \mathrm{S} 2$ & $\begin{array}{l}\mathrm{Rd} \leftarrow \mathrm{pc}, \text { next } \\
\mathrm{pc} \leftarrow \mathrm{Rx}+\mathrm{S} 2, \mathrm{CWP} \mathrm{CWP}-1\end{array}$ & $\begin{array}{l}\text { call e troca } \\
\text { janela }\end{array}$ \\
\hline callr & $\operatorname{Rd}, \mathrm{Y}$ & $\begin{array}{l}\mathrm{Rd} \leftarrow \mathrm{pc}, \text { next } \\
\mathrm{pc} \leftarrow \mathrm{pc}+\mathrm{Y}, \mathrm{CWP} \mathrm{CWP}-1\end{array}$ & $\begin{array}{l}\text { call relativo e troca } \\
\text { janela }\end{array}$ \\
\hline ret & $\mathrm{Rm}, \mathrm{S} 2$ & $\mathrm{pc} \leftarrow \mathrm{Rm}+\mathrm{S} 2, \mathrm{CWP} \leftarrow \mathrm{CWP}+1$ & ret. e troca janela \\
\hline ldhi & $\mathrm{Rd}, \mathrm{Y}$ & $\mathrm{Rd}<31: 13>\leftarrow \mathrm{Y} ; \mathrm{Rd}<12: 0>\leftarrow 0$ & carr. high imediato \\
\hline getlpc & $\mathrm{Rd}$ & $\mathrm{Rd} \leftarrow$ last $\mathrm{pc}$ & lê últim. cont. prog. \\
\hline getpsw & $\mathrm{Rd}$ & $\mathrm{Rd} \leftarrow \mathrm{PSW}$ & carr. prog. stat. word \\
\hline putpsw & $\mathrm{Rm}$ & $\mathrm{PSW} \leftarrow \mathrm{Rm}$ & arm. prog. stat. word \\
\hline time & $\mathrm{Rs}, \mathrm{S} 2, \mathrm{Rd}$ & $\mathrm{Rd} \leftarrow$ nciclos $-(\mathrm{Rs}+\mathrm{S} 2)$ & lê relógio \\
\hline
\end{tabular}




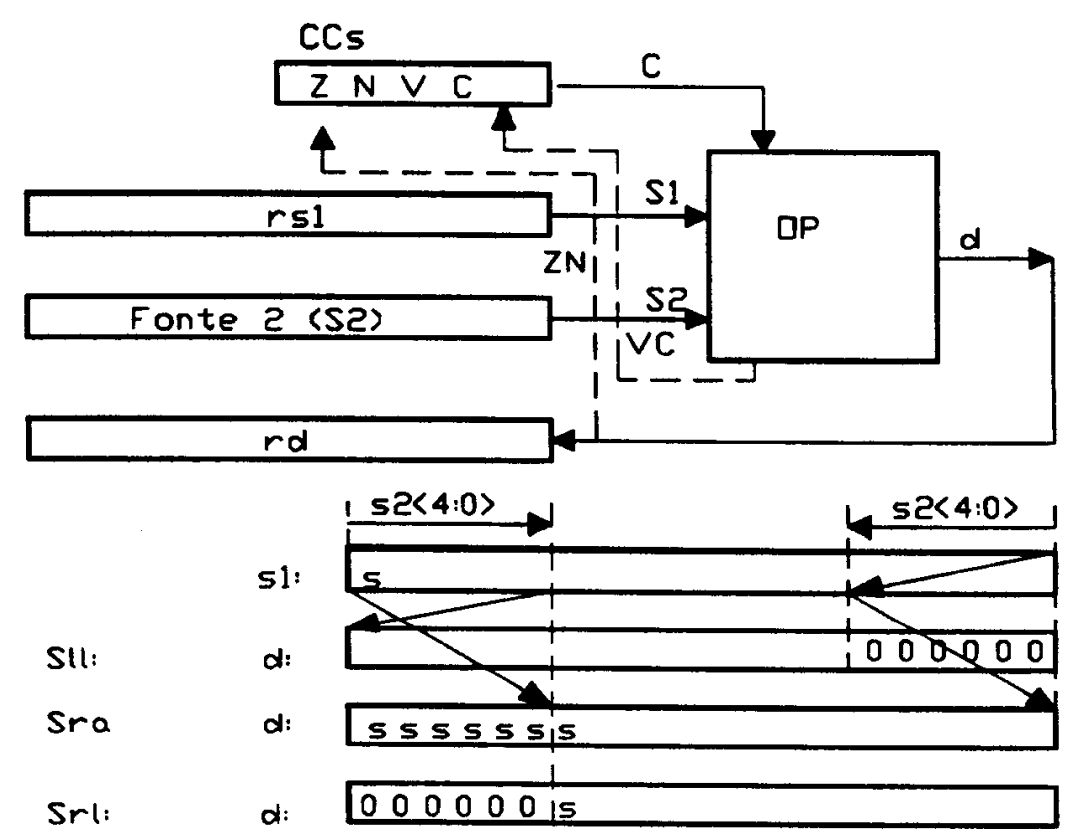

OP:

SHIFT: mostrado na figura anterior sll: sra: srl:

LÓGICAS: and: or: xor: $\mathrm{d}:=\mathrm{s} 1$ OP $\mathrm{s} 2$

ARITMÉTICAS: add: $\quad \mathrm{d}:=\mathrm{s} 1+\mathrm{s} 2$

addc: $\quad \mathrm{d}:=\mathrm{s} 1+\mathrm{s} 2+\mathrm{C}$

sub: $\quad \mathrm{d}:=\mathrm{s} 1-\mathrm{s} 2$ (int: $\mathrm{d}:=\mathrm{s} 1+\operatorname{not}[\mathrm{s} 2]+1)$

subc: $\quad \mathrm{d}:=\mathrm{s} 1-\mathrm{s} 2-\operatorname{not}[\mathrm{C}](\mathrm{d}:=\mathrm{s} 1+\operatorname{not}[\mathrm{s} 2]+\mathrm{C})$

subi: subci: $\quad \mathrm{d}:=\mathrm{s} 2-\mathrm{s} 1\{-\operatorname{not}[\mathrm{C}]\}$

CCs: atualizadas se bit SCC estiver em ON

$\mathrm{Z}:=[\mathrm{d}==0] ; \mathrm{N}:=\mathrm{d}<31>$

shift, instr. lógicas: $\mathrm{V}:=0 ; \mathrm{C}:=0$

aritméticas: $\mathrm{V}:=[\mathrm{Compl} 2 \mathrm{em} 32$ bits se ocorrer overflow]

adições: $\mathrm{C}:=$ carry $<31>$ para $<32>(\mathrm{p} / \mathrm{s} 1$ e $\mathrm{s} 2$ sem sinal $)$

subtrações: $\mathrm{C}:=$ not $[$ borrow $<31>$ para $<32>$ ] $(\mathrm{p} / \mathrm{s} 1$ e s2 sem sinal $)$

Figura A.1: Instruções shift e lógicas aritméticas 


\section{A.2.2 Instruções load}

Instruções load acessam a memória de dados, para leitura. Nesta versão do simulador, esta memória possui $512 \mathrm{~K}$ bytes [00000-80000]. O endereço efetivo para acesso, é dado pela soma de rs1 e S2(13 bits), para loads registrador-indexado. Existem instruções load para palavra (word), meia palavra (halfword) e byte. Para os dois últimos casos existe a possibilidade de load de quantidades com sinal ou sem sinal. Uma vez lido a parte desejada do dado endereçado, ele será alinhado à direita e será feita uma extensão de sinal ou preenchimento com zeros (§3.1.2), e só depois é que será escrito em rd. A parte desejada é definida pela instrução, e pelos dois bits menos significativos do endereço efetivo. As condições de código (CCs), poderão ser atualizadas, opcionalmente.

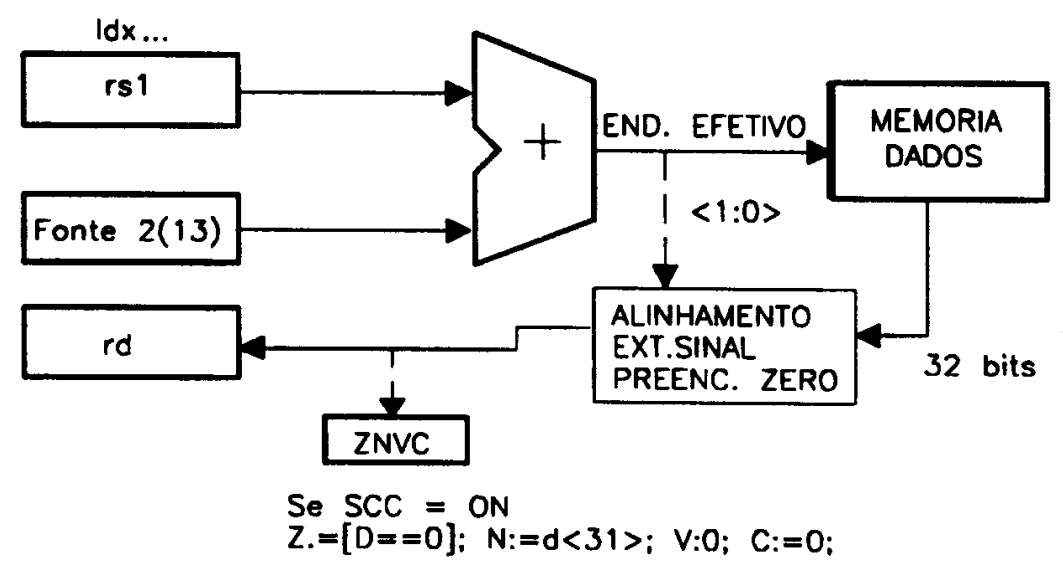

Figura A.2: Instruções load 


\section{A.2.3 Instruções store}

Instruções store realizam acesso à memória de dados, para escrita. O endereço efetivo para este acesso é calculado de forma similar a instruções load, somando-se rs1 com S2. Deve-se notar que os operandos estão invertidos (ver tabela A.1). A UCP alinhará corretamente o dado, de acordo com o que estiver especificado na instrução, e pelos dois bits menos significativos do endereço efetivo.

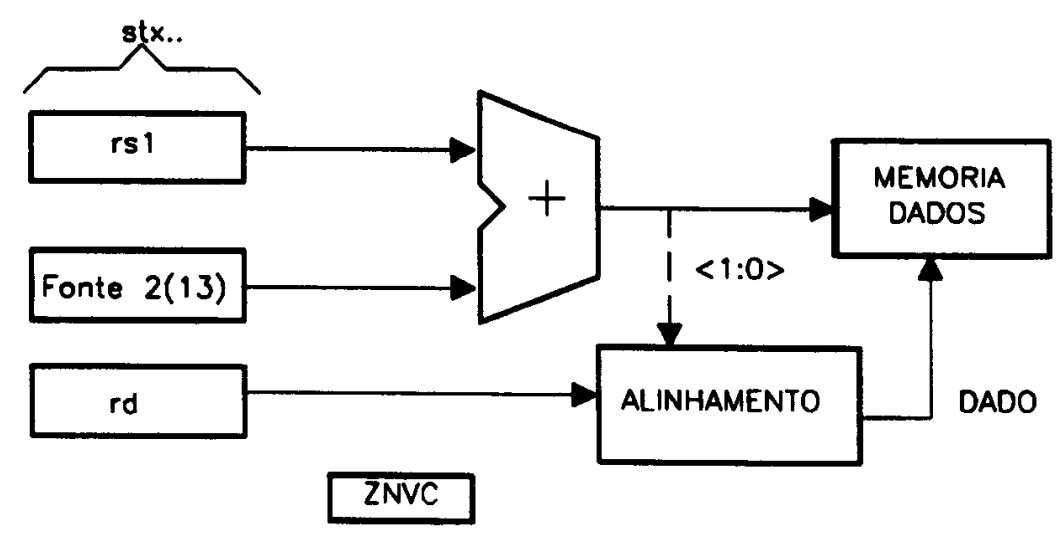

SCC DEVE ESTAR EM OFF

Figura A.3: Instruções store

\section{A.2.4 Instruções de transferência de controle}

Instruções de transferência de controle são compostas pelo grupo de jumps, calls e ret (tab. A.1). Instruções jump (condicional e incondicional) e call computam o endereço efetivo para desvio, como instruções load, com a diferença que aqui existe além do modo registrador-indexado, o modo $\mathrm{PC}$-relativo que soma um offset ao conteúdo de $\mathrm{PC}$, gerando o endereço efetivo para salto. 


\section{APÊNDICE A. CARACTERÍSTICAS ARQUITETURAIS}

Uma vez calculado o endereço, é feito um teste de alinhamento (o endereço deve ser divisível por 4); caso esteja errado, a execução será abortada e uma mensagem indicará a instrução errada. A tabela A.2 mostra as condiçōes de jump, e a figura A.4 mostra instruções de transferência de controle e o esquema de delayed jump (\$2.4). 

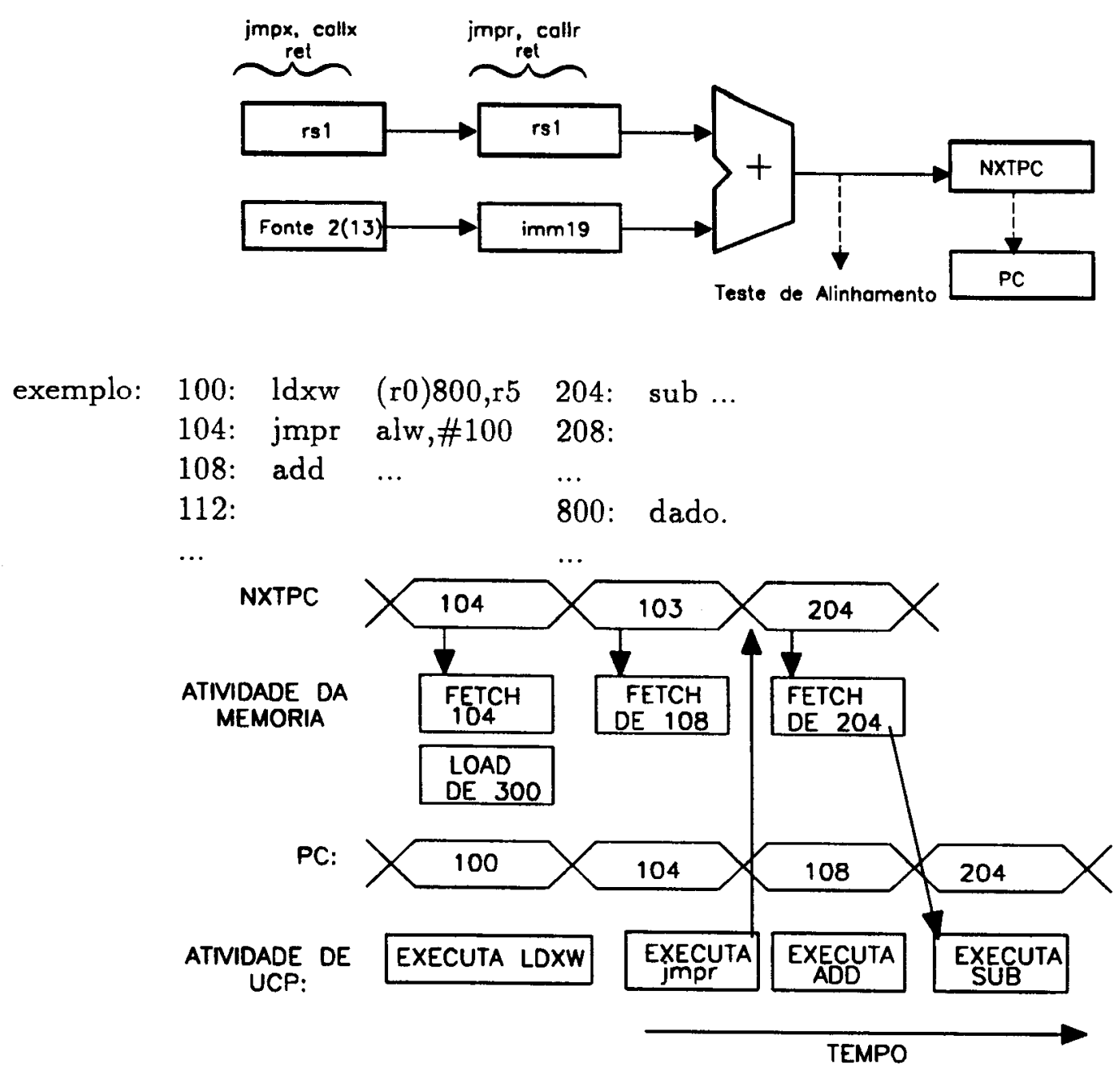

Figura A.4: Transferência de controle e jump atrasado 


\section{A.2.5 Miscelânia de instruções}

Este grupo de instruções foram criadas de forma a suportar determinadas funções como a instrução ldhi (tab. A.1) que é usada para se carregar uma constante de 19 bits na porção mais significativa do registrador. Esta instrução é adequada quando se deseja constantes imediatas maiores que 13 bits (Compl2).

exemplo:

ldhi $\quad \mathrm{r} 5, \# 3 \quad \mathrm{r} 5 \leftarrow 0 \times 00006000$

add $\quad \mathrm{r} 5, \# 32, \mathrm{r} 5 \quad \mathrm{r} 5 \leftarrow 0 \times 00006020$

A instrução getlpc é usada para salvar o conteúdo de LSTPC em um registrador rd. É normalmente utilizada após uma instrução call para salvar endereço de retorno.

As instruções getpsw e putpsw são utilizadas para se manipular o registrador de estado do processador (processor status word). A maneira de se interpretar o registrador utilizado em uma destas instruções é mostrada abaixo:

\begin{tabular}{ll} 
& BIT \\
\hline CWP: ponteiro para janela corrente & $<12: 10>$ \\
SWP: ponteiro para janela salva & $<9: 7>$ \\
Z: condição de código zero & $<3>$ \\
N: condição de código negativo & $<2>$ \\
V: condição de código overflow & $<1>$ \\
C: condição de código carry & $<0>$
\end{tabular}

As instruções de manipulação de interrupção, respectivamente calli e reti ainda não estão implementadas nesta versão do simulador.

A instrução time foi implementada com o intuíto de se acessar o contador de ciclos de máquina deste simulador, e é adequada para se medir tempos de computação uma vez que se sabe o valor do clock básico desta UCP. Esta instrução pertencerá somente ao simulador. 
Tabela A.2: Condições de jump

\begin{tabular}{|c|c|c|}
\hline Símbolo & Nome & Significado \\
\hline gt & maior que (cmp com sinal) & $\overline{(N \oplus V)+Z}$ \\
\hline le & menor ou igual (cmp com sinal) & $(N \oplus V)+Z$ \\
\hline ge & maior ou igual (cmp sinal) & $\overline{(N \oplus V)}$ \\
\hline lt & menor que (cmp sinal) & $(N \oplus V)$ \\
\hline hi & maior que (cmp sem sinal) & $\overline{\bar{C}+Z}$ \\
\hline los & menor ou igual (cmp sem sinal) & $\bar{C}+Z$ \\
\hline lo & menor que (cmp sem sinal) & $\bar{C}$ \\
\hline his & maior ou igual (cmp sem sinal) & $C$ \\
\hline pl & positivo (teste com sinal) & $\bar{N}$ \\
\hline $\mathbf{m i}$ & negativo (teste com sinal) & $N$ \\
\hline ne & não igual & $\bar{Z}$ \\
\hline eq & igual & $Z$ \\
\hline nv & não overflow (aritm. com sinal) & $\bar{V}$ \\
\hline $\mathbf{v}$ & overflow (aritm. com sinal) & $V$ \\
\hline alw & incondicional & 1 \\
\hline
\end{tabular}

símbolo: usado na instrução exemplo: jmpx ge,(r6)912

$\begin{array}{ll}\oplus & \text { ou exclusivo } \\ \mathbf{N} & \text { flag negativo } \\ \mathbf{V} & \text { overflow } \\ \mathbf{Z} & \text { zero } \\ \mathbf{C} & \text { carry }\end{array}$




\section{Bibliografia}

[Alma89] G.S.Almasi, A.Gottieb, Highly Parallel Computing, The Benjamin/Cummings Publishing Company,Inc 1989.

[Brow84] J.Browne, Understanding execution behavior of software systems, Computer, vol. 17, july 1984 .

[Cock83] J.Cocke and G.Radin, The IBM 801 mini-computer, IBM J.Res.Development vol.27, may 1983 .

[Clip86] Fairchild, CLIPPER Module, 32-bit microprocessor Product Description, Prentice Hall,Inc 1986.

[Clip87] Fairchild, CLIPPER, 32-bit microprocessor User's Manual, Prentice Hall,Inc 1987.

[Clip89] W.Hollingsworth, H.Sachs, and A.J.Smith, The Clipper Processor: Instruction Set Architecture and Implementation, Communications of the ACM, feb 1989.

[Colw85] R.P.Colwell et al, Computers, Complexity and Controversy, Computer, sep 1985.

[Croo86] J.G.Crookes, D.W.Balmer, S.T.Chew and R.J.Paul, A Three-Phase Simulation System Writtem in Pascal, Journal of the Operational Reasearch Society Vol.37,No.6, 1986.

[Flyn87] M.J.Flynn, C.L.Mitchell and J.M.Mulder, And Now a Case for More Complex Instruction Sets, Computer, sep 1987.

[Hama85] V.C.Hamacher, Z.G.Vranesic, S.G.Zaky, Computer Organization, McGraw Hill International Book Company, 1985. 
[Henn84] J.L.Hennessy, VLSI processor architecture, IEEE Trans. Computers, dec 1984.

[Hwan84] K.Hwang, F.A.Briggs, Computer Architecture and Parallel Processing, McGraw-Hill Book Company, 1984.

[Inte89] A Performance Report on The 386 Family of High Performance 32-bit Microprocessors, Intel Corporation, apr. 1989.

[Kate84] M.Katevenis, Reduced Instruction Set Computer for VLSI, ACM Doctoral Dissertation Award 1984, The MIT Press.

[KeRi88] B.W.Kernighan and D.M.Ritchie, The C Programming Language, 2nd Edition, Prentice Hall, 1988.

[LeCl82] H.M.Levy, D.W.Clark, On the use of benchmarks for measuring system performance, Comp. Arch. News, dec 1982.

[McNe87] K.J.McNeley and V.M.Milutinovic, Emulating a Complex Instruction Set Computer with a Reduced Instruction Set Computer, IEEE Micro, feb 1987.

[Milu87] C.E.Gimark and V.M.Milutinovic, A Survey of RISC Processors and Computers of the Mid-1980s, Computer, sep 1987.

[PaHe87] D.A.Patterson and J.Hennessy, Response to Computers, Complexity and Controversy, Computer, nov 1985.

[PaPi82] D.A.Patterson and R.S.Piepho, Acessing RISCs in High-Level Language Support, IEEE Micro, nov 1982.

[PaSe81] D.A.Patterson, C.Séquin, RISC I: A Reduced Instruction Set VLSI Computer, Proc. of the 8th Symposium on Computer Architecture, ACM SIGARCH CAN 9.3, may 1981.

[PaSe82] D.A.Patterson, C.Séquin, A VLSI RISC, Computer, sep 1982.

[Patt85] D.A.Patterson, Reduced Instruction Set Computers, Communications of the ACM, jan 1985. 
[Pino88] G.A.Pino, L.A.Marrone, Arquitecturas RISC, EBAI 1988.

[Radi83] G.Radin, The 801 Minicomputer, IBM J. Res. Development, may 1983.

[RaWe87] R.Weiss, RISC processors: the new wave in computers systems, Computer Design, may 15, 1987.

[Smit82] A.Smith, Cache Memories, ACM Computing Surveys, vol.14, sep 1982.

[Stal88] W.Stallings, Reduced Instruction Set Computer Architecture, proc. of the IEEE, vol 76, jan 1988 .

[Ston75] H.S.Stone et al, Introduction to Computer Architecture, Science Research Associates,Inc 1975.

[SunM88] A RISC Tutorial, Sun Microsystems, Inc.,1988.

[Tami89] Y.Tamir,F.Valente, Comunicação Privada, E-mail via BITNET (IFQSCUCLA), fev 1989

[TaSe83] Y.Tamir, C.Séquin, Strategies for Managing the Register File in RISC, IEEE Transactions on Computers, vol.C-32, nov 1983.

[Tane78] A.S.Tanenbaum, Implications of Structured Programming for Machine Arquitecture, Communications of the ACM, mar 1978.

[Tane84] A.S.Tanenbaum, OPERATING SYSTEMS - Design and Implementation, Prentice-Hall,Inc 1987.

[Weic84] R.P.Weicker, Dhrystone: A Synthetic Systems Programming Benchmark, Communications of the ACM, oct 1984 .

[Wulf81] W.A.Wulf, Compilers and Computer Architecture, Computer, jul 1981. 